\title{
Internal waves and vertical mixing in the Storfjorden Polynya, Svalbard
}

\author{
F. P. Jardon, ${ }^{1}$ P. Bouruet-Aubertot,${ }^{1}$ Y. Cuypers, ${ }^{1}$ F. Vivier, ${ }^{1}$ and A. Lourenço ${ }^{1}$ \\ Received 27 December 2010; revised 23 September 2011; accepted 3 October 2011; published 24 December 2011.
}

[1] Latent heat polynya are preferential sites for dense water formation through brine release. The combined action of winds and heat loss leading to sea ice fracture followed by the reactivation of sea ice formation drives this process of dense water formation. The impact of high-frequency dynamics, and especially internal wave breaking, on this process is investigated here, with the analysis of hydrographic observations collected from a drifting mooring in Storfjorden, Svalbard. The main frequency components of the barotropic tide are first revealed by the analysis of a 23-day time series of pressure data. Interestingly the same frequency peaks are isolated by a spectral analysis of isopycnal displacements, suggesting a tidal forcing for these baroclinic waves. The hypothesis of local generation in the Storfjorden is next examined and numerous sites of potential generation are identified specifically for semi-diurnal and sixth-diurnal frequencies. Diurnal baroclinic waves, however, do not appear to be locally generated, but rather popagate cyclonically along the shelf as internal Kelvin waves. The characteristic of these waves and their energy flux are then inferred. A parameterization of dissipation based on the potential energy of the internal wavefield is next proposed and an upper bound for dissipation rate within overturning regions is provided. The most vigorous mixing is associated with brine release events (i.e. strong vertical mixing through thermohaline convection) with eddy diffusivities of up to $10^{-3} \mathrm{~m}^{2} \mathrm{~s}^{-1}$. The background mixing (likely associated with internal wave breaking), however, displays values within $\left[10^{-6}, 10^{-4}\right] \mathrm{m}^{2} \mathrm{~s}^{-1}$. This background mixing contributes about $O(0.1) \mathrm{W} \mathrm{m} \mathrm{m}^{-2}$ to the vertical heat flux with a net heating in the bottom layer and cooling in the upper layer. Local heating and cooling rates of the order of $0.025^{\circ} \mathrm{C}$ month ${ }^{-1}$ are obtained which is significant with respect to the $0.1{ }^{\circ} \mathrm{C}$ temperature difference between the bottom and surface layers.

Citation: Jardon, F. P., P. Bouruet-Aubertot, Y. Cuypers, F. Vivier, and A. Lourenço (2011), Internal waves and vertical mixing in the Storfjorden Polynya, Svalbard, J. Geophys. Res., 116, C12040, doi:10.1029/2010JC006918.

\section{Introduction}

[2] Vertical mixing and high frequency dynamics (mostly internal gravity waves) impact larger scale motions. Interestingly this impact strongly differs depending on the region of interest. At high latitudes, strong mixing is triggered by the entrainment associated with deep water formation. Nevertheless mixing driven by internal wave breaking, though much weaker, also plays a role in high latitude dynamics. Through diffusive heat transfer, mixing at high latitudes causes variations in ice thickness and water mass transformations. The role of barotropic and baroclinic tides can be very different. In regions of thin ice, such as coastal polynyas, barotropic tides can induce fracture zones resulting in lead

\footnotetext{
${ }^{1}$ Laboratoire d'Océanographie et du Climat: Expérimentaions et Approches Numériques, Institut Pierre Simon Laplace, Université Paris VI, Paris, France.

Copyright 2011 by the American Geophysical Union. 0148-0227/11/2010JC006918
}

formation, which enables the generation of sea ice and deep water production through brine rejection. On the other hand, mixing induced by internal tides can either lead to an increase or a decrease in ice thickness depending on the vertical profiles of temperature and diffusivity. These processes have been very well observed near Maud rise in the Southern Ocean [Lindsay et al., 2008]. Also, vertical mixing can be of importance in regions of deep water formation by inducing dilution it can induce which in turn will condition the cascading of these dense waters into the deep ocean. These questions are addressed here in the Storfjorden, an Arctic polynya in the Svalbard archipelago, which is an active site of deep water formation that contributes about 5 to $13 \%$ of the Arctic deep water [Quadfasel et al., 1988; Schauer, 1995].

[3] As ice caps the ocean and limits mixing by the winds, internal ocean dynamics become a prominent source of mixing, especially in coastal regions and more specifically in the Storfjorden. In this context turbulent mixing induced by internal wave breaking is of particular importance. The internal wavefield has some specific features in the Arctic 
that are related to its two main energy sources, the atmospheric forcing and the tides. First the generation of internal waves by inertial pumping at the base of the mixed layer is strongly limited by the ice cover. Second, the propagation of baroclinic tides generated by barotropic tidal currents flowing over topography such as continental shelves or sea mounts [Hendershott, 1981] is partly inhibited. Indeed the semi-diurnal tidal component M2 and the diurnal components are beyond their critical latitude hence they can not exist as freely propagating waves except within specific waveguides [Gerkema and Shrira, 2005]. Nevertheless, forced baroclinic semi-diurnal and diurnal tides can be generated beyond their critical latitude as evidenced in McMurdo Sound [Albretch et al., 2006]. Also barotropic tidal energy can be transferred into a baroclinic coastal wave or topographic shelf waves [e.g., Padman et al., 1992].

[4] As a result of the ice cover, the average energy level of the Arctic internal wavefield is smaller by at least one order of magnitude than that of the open-ocean internal wavefield defined by Garrett and Munk [Levine et al., 1985; Levine, 1990; Padman and Dillon, 1991]. However observations have revealed a contrasting situation with regions of enhanced energy levels of the Arctic internal wavefield [e.g., D'Asaro and Morison, 1992; Plueddemann, 1992]. Some of these regions are clearly identified as sites of conversion from barotropic tides to baroclinic tides, the Yermak Plateau being one of the most studied [Fer et al., 2010; I. Fer and F. Geyer, Mixing in the marginal ice zone near the Yermak Plateau. Part II: Tidal forcing, submitted to Journal of Physical Oceanography, 2009], as well as the surroundings of Bear island [Vlasenko et al., 2003]. Other energetic regions less identified are related to intermittent generation events such as wave radiation induced by the ice drift [Rigby, 1976; Halle and Pinkel, 2003], or by convection associated with brine rejection during ice-formation period in polynya regions [Morison, 1986]. Also the mesoscale eddy field plays a role in the generation of near-inertial waves through adjustment processes as well as in the redistribution of the near-inertial wave energy trapped within anticyclonic eddies [Olbers, 1983; Halle and Pinkel, 2003].

[5] In the Storfjorden coastal polynya (Svalbard) (Figure 1), these different mechanisms of generation are likely to occur. However, there have been very few measurements that attempted to characterize the internal wavefield. The main observations were inferred from ADCP (Acoustic Doppler Current Profiler) measurements at the sill [Fer et al., 2004] revealing the dominance of tidal currents. This suggests the possibility of baroclinic tide generation that could then propagate into the fjord [Fer and Widell, 2007]. This question is addressed in this work using high frequency measurements.

[6] Our knowledge of the spatial distribution of mixing relies on estimates based on fine-scale parameterizations [e.g., Naveira Garabato et al., 2004] or on microstructure measurements [e.g., Padman and Dillon, 1991; Sundfjord et al., 2007; Fer and Widell, 2007; Rainville and Winsor, 2008]. The fine-scale parameterizations and the microstructure measurements differ greatly, which is consistent with the strongly variable distribution of internal wave energy and the intermittency of mixing events [Rainville and Winsor, 2008]. The location of regions of enhanced mixing are correlated with major topographic features [Padman and Dillon, 1991; Perkin and Lewis, 1984; Fer et al., 2010], the pycnocline, the surface layer below the ice [Halle and Pinkel, 2003] and the overflow of the dense plume out of the fjord [Fer et al., 2004]. We characterize here turbulent mixing and its relationship with the internal wavefield in the Storfjorden through the analysis of time series of temperature and salinity acquired every 2 minutes.

[7] The experiments were carried out in in late March 2007 with two ice-tethered moorings deployed in the northwestern part of the Storfjorden. These moorings drifted southward for a 10-day period, allowing further documentation of the spatial distribution in the western part of the fjord of water masses and their characteristics in late winter. Here we use these measurements to analyze the influence of mixing generated by high-frequency variability in the upper ocean layer as well as its potential source of energy. The article is organized as follows: the experimental data and setup is first introduced, barotropic tides are next characterized from a one month time series of bottom pressure in a second section. The third section is dedicated to internal waves. The main components of the baroclinic wavefield are analyzed and their characteristics inferred as well as energy fluxes. Then estimates of mixing are computed from a fine-scale parameterization and the impact on vertical heat flux is eventually addressed. Results are summarized and discussed in the last section.

\section{Experimental Setup and Data}

[8] On 23 March an ice-tethered mooring (Middle Mooring: MM) equipped with autonomous CTD (conductivitytemperature-depth) sensors was deployed (Figure 1). The vertical resolution was set to $5 \mathrm{~m}$, and the time sampling to 2 minutes of these sensors were set in order to resolve the internal wavefield. Additionally, two secondary instruments were deployed: (1) a prototype buoy "Ice-T" providing information about the relative velocity between the sea ice and the upper ocean layer (F. Vivier et al., "Ice-T": An autonomous buoy to measure ice thickness and thermal fluxes in sea ice, manuscript in preparation, 2011) and (2) a peripheral mooring (Eastern Mooring: EM). Both moorings also included two NKE SP2T instruments, recording pressure and temperature at $0.5 \mathrm{~m}$ and $15 \mathrm{~m}$ with a $20 \mathrm{~s}$ sampling period. The experiment was installed over a $40 \mathrm{~cm}$ thick land fast ice with positive freeboard, covered by $20 \mathrm{~cm}$ of snow. The MM was equipped with 12 sensors to have a fine vertical resolution. It included five autonomous conductivitytemperature sensors (Sea-Bird SBE37MP pumped Microcat) located at 1.8, 10, 20, 30 and $55 \mathrm{~m}$ depth, respectively, and seven autonomous temperature sensors (RBR TR1050) at $1.8,5,15,25,35$ and $55 \mathrm{~m}$, respectively. Microcat sensors record temperature and conductivity with high accuracy $\left(0.002^{\circ} \mathrm{C}\right.$ and $\left.0.003 \mathrm{mS} \mathrm{cm}^{-1}\right)$. The three deepest Microcats were equipped with pressure sensors to detect possible tilt of the mooring line (accuracy is 0.25 dbar for instruments at $20 \mathrm{~m}$ and $55 \mathrm{~m}$, and $0.7 \mathrm{dbar}$ at $30 \mathrm{~m}$ ). RBR sensors provided a temperature measurement only, also with high precision $\left(0.002^{\circ} \mathrm{C}\right)$. The EM was equipped with $3 \mathrm{RBR}$ sensors located at nominal depths of $0.2,0.7$ and $1.2 \mathrm{~m}$. All moored instruments were set to a high sampling rate (120 s for Microcat, $5 \mathrm{~s}$ for RBR) to capture the high-frequency variability associated with internal waves. Both moorings also included two NKE SP2T instruments, recording pressure and temperature at $0.5 \mathrm{~m}$ and $15 \mathrm{~m}$ with a $20 \mathrm{~s}$ sampling period. We discard 

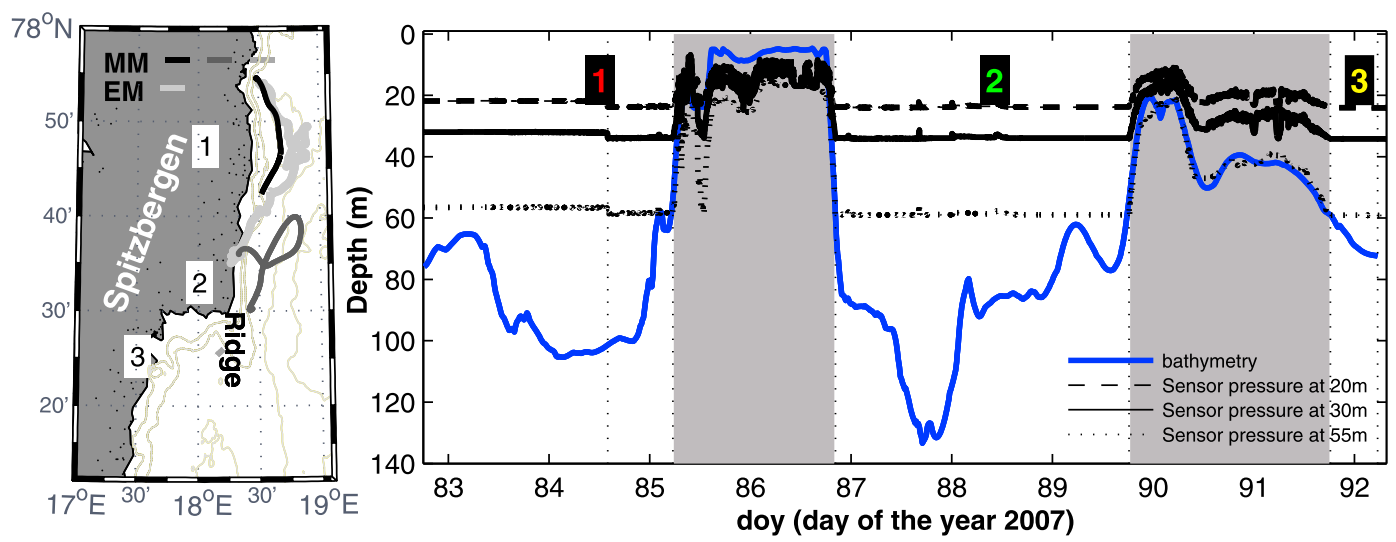

Figure 1. (left) Mooring line trajectory superimposed on Storfjorden bathymetry from the $500 \mathrm{~m}$ resolution database of Skogseth et al. [2005a]. The white line denotes the eastern mooring (EM). The main mooring (MM) trajectory is divided into three segments corresponding to regions deeper than $50 \mathrm{~m}$ (red, green yellow lines for segments 1, 2 and 3, respectively). (right) Topographic features intercepted by the main mooring during its drift.

the less accurate temperature data from these sensors, from which only pressure ( 0.3 dbar accuracy) measurements were used hereafter.

[9] A few hours after the deployment intense southwesterly winds and a strong storm dislocated the ice initiating the mooring drifts. The instruments of MM drifted for 10 days with a trajectory displayed on Figure 1. In addition the deepest instruments were dragged on the bottom in two instances, therefore the record has been split into three valid segments (Figure 1). After once week adrift, the Eastern mooring got blocked for 23 days over shallow depth near the coast, thus becoming a perfect tide gauge through the bottom pressure time series.

[10] The time convention used hereafter is that day of year 2007 (day): day 0.5 corresponds to UTC noon on 1 January 2007. The data time grid therefore extends from day 82 (23 March 2007) to day 92 (2 April 2007).

\section{Barotropic Tide}

[11] Tides play an important role as energy sources for oceanic mixing either directly through turbulent dissipation in boundary layers or indirectly through the generation of baroclinic tides. Our analysis of tidal variability is based on a 23-day time series of bottom pressure from the EM.

[12] The main frequency components of the pressure signal are evidenced in Figure 2 which displays frequency spectrum computed using a multitaper method (MTM) [Percival and Walden, 1993]. This method reduces the variance of spectral estimates by using a small set of tapers yielding a better estimate, the tradeoff being a reduction of the spectral resolution. Thus the different tidal components in both the semidiurnal and quarter-diurnal frequency bands could not be separated. The major peak of the spectrum is at semi-diurnal frequency and it comprises both the lunar and solar semidiurnal tidal frequencies, M2 and S2 equal to $0.0805 \mathrm{cph}$ and $0.0833 \mathrm{cph}$, as well as the inertial frequency which has an average value of $0.0814 \mathrm{cph}$ taken at the averaged latitude of $77.61^{\circ} \mathrm{N}$. The two other peaks at the diurnal and quarter diurnal frequencies are of the same order of magnitude and of about 25 times smaller than the semi-diurnal peak.
[13] We next performed an harmonic analysis of tidal constituents [Pawlowicz et al., 2002] which allows, owing to the length of the time series, to separate on the one hand the luni-solar diurnal, K1, from the principal lunar diurnal, $\mathrm{O} 1$, and on the other hand, the lunar semi-diurnal component, M2, from the solar semi-diurnal component, S2 as well as the three tidal frequencies, M4, MS4 and S4, in the quarter-diurnal frequency band. The inertial frequency $(f \sim 0.0814 \mathrm{cph})$ could not be distinguished from the lunar semi-diurnal frequency $(M 2 \sim 0.0805 \mathrm{cph})$ due to an insufficient spectral resolution $(\sim 0.0018 \mathrm{cph})$.

[14] Accordingly, the barotropic semi-diurnal components, M2 and S2, account for almost $55 \%$ and $25 \%$ of the variance with amplitudes around 26.7 and $16.5 \mathrm{~cm}$, respectively (see Table 1). Other significant tidal constituents are K1 with amplitude around $4.7 \mathrm{~cm}$, and the so-called shallow water tides, M4, MS4 and S4. These harmonics have amplitudes between 1.5 and $4.5 \mathrm{~cm}$ and they explain a small fraction $(3 \%)$ of the total variance (see Table 1 ). We display also in Figure 2 and Table 1 the diurnal and semi-diurnal tidal components $(\mathrm{O} 1, \mathrm{~K} 1, \mathrm{M} 2$ and $\mathrm{S} 2)$ as predicted by the Arctic Ocean Tide Inversed Model, AOTIM [Padman, 2004]. This model which has a $5 \mathrm{~km}$ resolution over the Arctic and assimilates tidal height data provides estimates that are in very good agreement with our in situ measurements. Therefore the AOTIM will be used for further analyzes in the following.

[15] Also, these results are in agreement with tidal analysis based on time series of current profiles during almost 4 days in the west part of the basin, close to the Freemansundet channel by Skogseth et al. [2008]. They found that the dominant tidal constituent is the semidiurnal and explains almost $99 \%$ of the barotropic tidal pattern, while the other tidal constituents, $\mathrm{K}_{1}, \mathrm{M}_{4}$ and $\mathrm{M}_{6}$ represents less than $1 \%$ of the explained variance. Also Fer et al. [2003] performed a tidal analysis using one year time series of current data collected in the southwestern coast of Spitsbergen at around $300 \mathrm{~m}$ depth. They found that diurnal (K1 and $\mathrm{P} 1$ ) and semidiurnal tide (M2 and S2) components were dominant. They also suggest the presence of baroclinic tides 


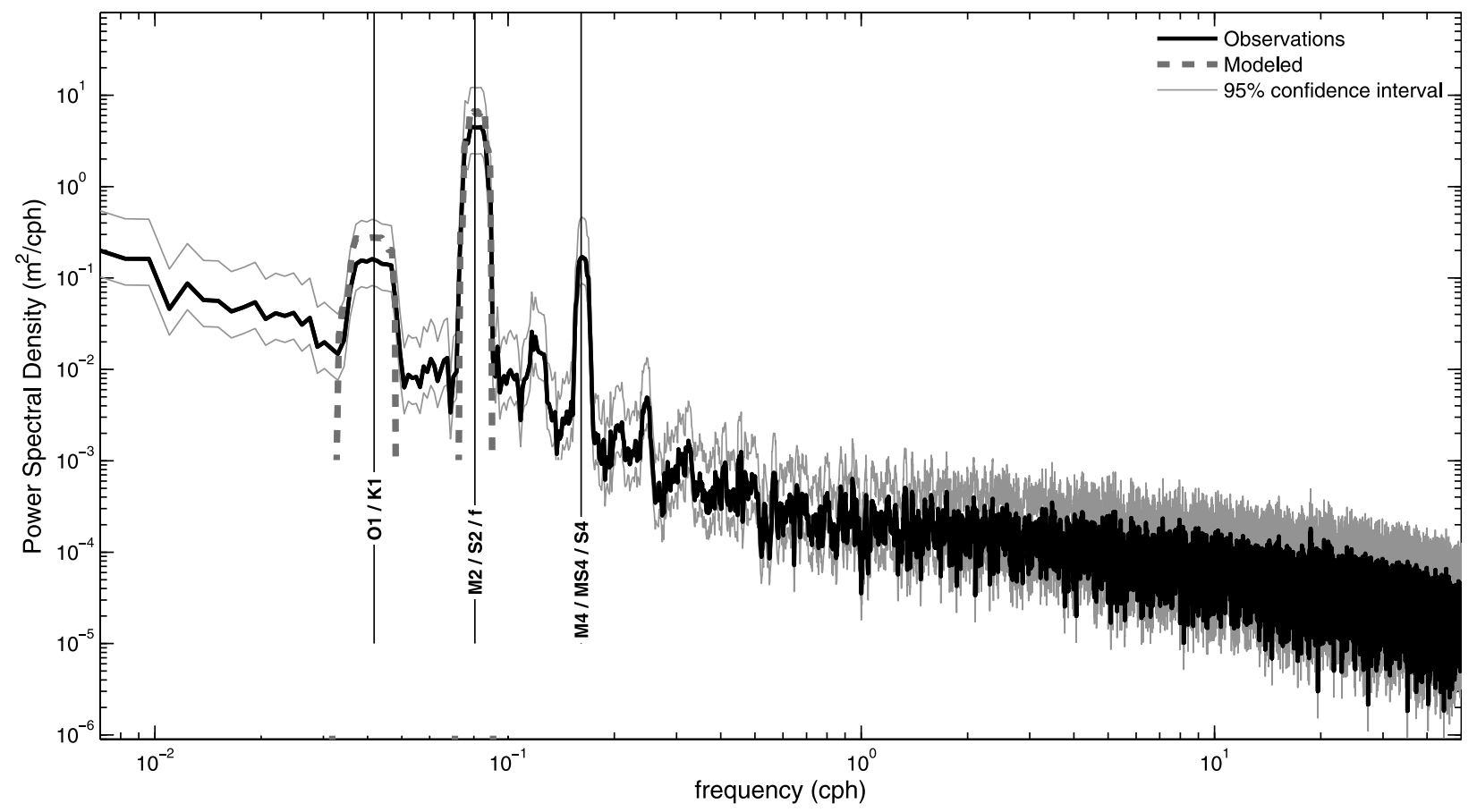

Figure 2. Frequency spectrum from bottom pressure time series at EM and the $95 \%$ confidence interval (black and grey lines, respectively). In addition diurnal and semi-diurnal barotropic tide (O1, K1, M2 and S2) as inferred from AOTIM are shown (grey dashed line). Some principal tide constituents and the inertial frequency are indicated. Axes are in logarithmic scale.

based on the depth-changing sign of semi-diurnal component eccentricity.

\section{Internal Waves}

\subsection{Main Components}

\subsubsection{Baroclinic Waves at Tidal Frequencies}

[16] The temporal variability of potential density anomalies, computed as the deviation from mean potential density at each depth, reveals oscillations at different timescales (Figure 3). High frequency variability is observed during all segments, and is particularly accentuated below $40 \mathrm{~m}$ around day 83.5 and 84.75 during segment 1 and over the whole water column between days 87.75 and 89 during segment 2. Some of these timescales observed during segments 1 and 2 are super-inertial, for instance likely the principal solar (S2) and the quarter-diurnal, which suggests the presence of internal gravity waves. Furthermore, sub-inertial oscillations at diurnal and semi-diurnal frequencies (the principal lunar M2) can be noticed indicating the presence of forced bar-

Table 1. Significant Tidal Constituents From Bottom Pressure Data at the Eastern Mooring

\begin{tabular}{cccccc}
\hline & \multirow{2}{*}{\begin{tabular}{c} 
Frequency \\
\cline { 3 - 4 } Constituents
\end{tabular}} & \multicolumn{2}{c}{ Amplitude $(\mathrm{cm})$} & & \multirow{2}{*}{$\begin{array}{c}\sigma_{\exp }^{2} \\
(\%)\end{array}$} \\
\cline { 3 - 4 } O1 & 0.0387 & $1.4 \pm 1.1$ & $2 \pm 1.4$ & $234.06 \pm 57.01$ & 0.33 \\
K1 & 0.0417 & $4.75 \pm 1.2$ & $7.3 \pm 5.2$ & $162.01 \pm 15.5$ & 2.3 \\
M2 & 0.0805 & $26.71 \pm 5.7$ & $25.10 \pm 17$ & $116 \pm 10.3$ & 55.3 \\
S2 & 0.0833 & $16.45 \pm 4.7$ & $10.6 \pm 7.5$ & $173.7 \pm 17.54$ & 25.3 \\
M4 & 0.1610 & $3.68 \pm 1.0$ & - & $241.2 \pm 14.9$ & 1.05 \\
MS4 & 0.1638 & $4.65 \pm 0.8$ & - & $291.9 \pm 11.7$ & 1.72 \\
S4 & 0.1666 & $1.46 \pm 0.8$ & - & $342.03 \pm 31.6$ & 0.24 \\
\hline
\end{tabular}

oclinic tides. In order to characterize these waves and possibly their vertical propagation, we computed the amplitude and phase of each tidal component as well as their significance. Despite the short length of the potential density fluctuation time series (5 and 6 semi-diurnal cycles for segment 1 and 2, respectively) the diurnal (D: K1, O1), semi-diurnal (SD: M2, S2), tidal components, as well as M4 and M6, are significant, in agreement with pressure data harmonic analysis. In Figure 4 amplitude and phase for those components are displayed for segments 1 and 2 .

[17] The strongest variability is observed during segment 2 with the highest amplitude obtained for diurnal and semidiurnal tides (Figure 4), these two components represent up to $12 \%$ and $10 \%$, respectively, of the explained variance. Interestingly there is a slight decrease of the phase for increasing depth from $15 \mathrm{~m}$ indicating vertical phase propagation. These observations hold for segment 1 though the amplitudes of both components are smaller by about a factor of 2. Regarding shallow water tides (Figures $4 \mathrm{~b}$ and $4 \mathrm{~d}$ ), two constituents are significant, M4 and M6, however their percentage of variance is fairly small with values up to $4 \%$ (2.5\%) for M4 (M6). Phase propagation is evidenced for M6 component from below $35 \mathrm{~m}$ depth during segment 1 but only over a very limited depth interval during segment 2 . Note that a weak 6-hour period oscillation was isolated during segment 3 , however this analysis is limited by the short length of this time series and is not shown here.

[18] These results give evidence of baroclinic waves at tidal frequencies, namely freely propagating internal tides at $\mathrm{S} 2, \mathrm{M} 4$ and M6 and forced baroclinic tides at $\mathrm{K} 1$ and M2, both of them being beyond their critical latitude. This is consistent with the barotropic tidal signal analysis inferred 

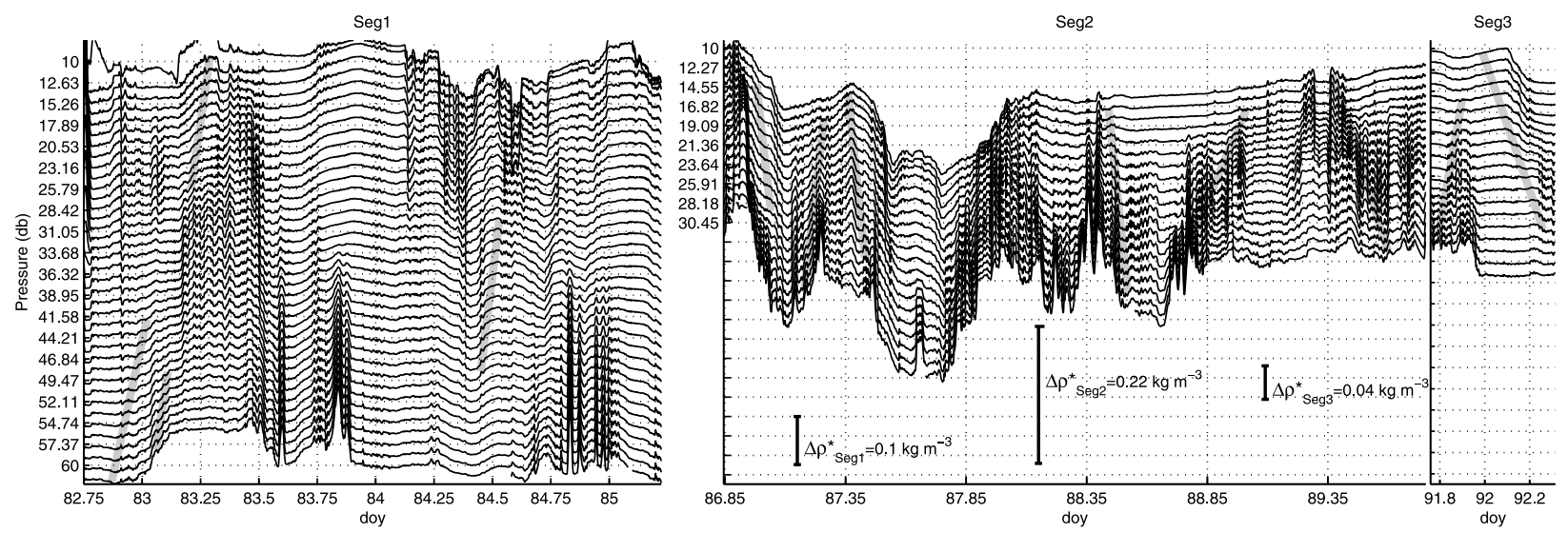

Figure 3. Time series of potential density fluctuations $\left(\left[\mathrm{kg} \mathrm{m}^{-3}\right]\right)$. The mean depth corresponding to each time series is indicated on the vertical axis. Note that the scale for density (y-axis) differs with depth and for each segment. The mean amplitude for each segment is presented. Grey lines identify the regions where vertical propagation of internal waves is evidenced.

from pressure data which has shown that these components are significant thus providing a possible forcing for baroclinic tides. This question of local generation of baroclinic tides is addressed in the following section, after a characterization of each wave component.

\subsubsection{Characterization of Baroclinic Waves:}

\section{Wavelength, Group Velocity and Energy Fluxes}

[19] The vertical wavelength was inferred from the phase profiles displayed in Figure 4 and the horizontal wavelength was computed assuming that the waves satisfy the dispersion relation for inertial-gravity waves

$$
k_{h}^{2}=k_{z}^{2} \frac{\omega^{2}-f^{2}}{N^{2}-\omega^{2}},
$$

where $k_{z}$ and $k_{h}$ are the vertical and horizontal wave number, respectively; $f$ is the inertial frequency and $N$ the buoyancy frequency, while $\omega$ is the frequency of each baroclinic tidal component. As shown in Table 2 , a vertical wavelength $\left(\lambda_{z}\right.$ $\left.=2 \pi / k_{z}\right)$ of $60 \mathrm{~m}$ and an horizontal wavelength $\left(\lambda_{h}=2 \pi / k_{h}\right)$ of $520 \mathrm{~m}$ are obtained for M6. Slightly higher values are obtained for $\lambda_{z}$ of K1, M2 and S2 within [140 m, $269 \mathrm{~m}$ ]. Note that for sub-inertial frequencies, K1 and M2, $k_{h}^{2}$ is negative in which case $1 / k_{h}$ give an order of magnitude of the attenuation of the wave amplitude along the horizontal. Values of a few $\mathrm{km}$ are obtained. This will provide useful information for determining whether a forced baroclinic wave generated locally in the Storfjorden can possibly be detected by our mooring measurements.

[20] The vertical energy flux $E_{f}$ was next computed using the following expression:

$$
E_{f}=E_{t} c_{g_{z}}
$$

where $c_{g_{z}}$ is the vertical group velocity and $E_{t}$ the total energy density, computed as $\mathrm{E}_{p}+\mathrm{E}_{k}$ (potential plus kinetic energy). The total energy is inferred using polarization relations for linear internal waves

$$
\frac{\left\langle E_{p}\right\rangle}{\left\langle E_{k}\right\rangle}=\frac{N^{2}\left(\omega^{2}-f^{2}\right)}{\omega^{2}\left(N^{2}-f^{2}\right)+f^{2}\left(N^{2}-\omega^{2}\right)} .
$$

[21] The energy flux for diurnal, semi-diurnal and M6 baroclinic tidal components is shown in Figure 5. Note that regarding diurnal frequencies, only $\mathrm{K} 1$ is computed because of its higher contribution than $\mathrm{O} 1$ (Table 1). In the case of
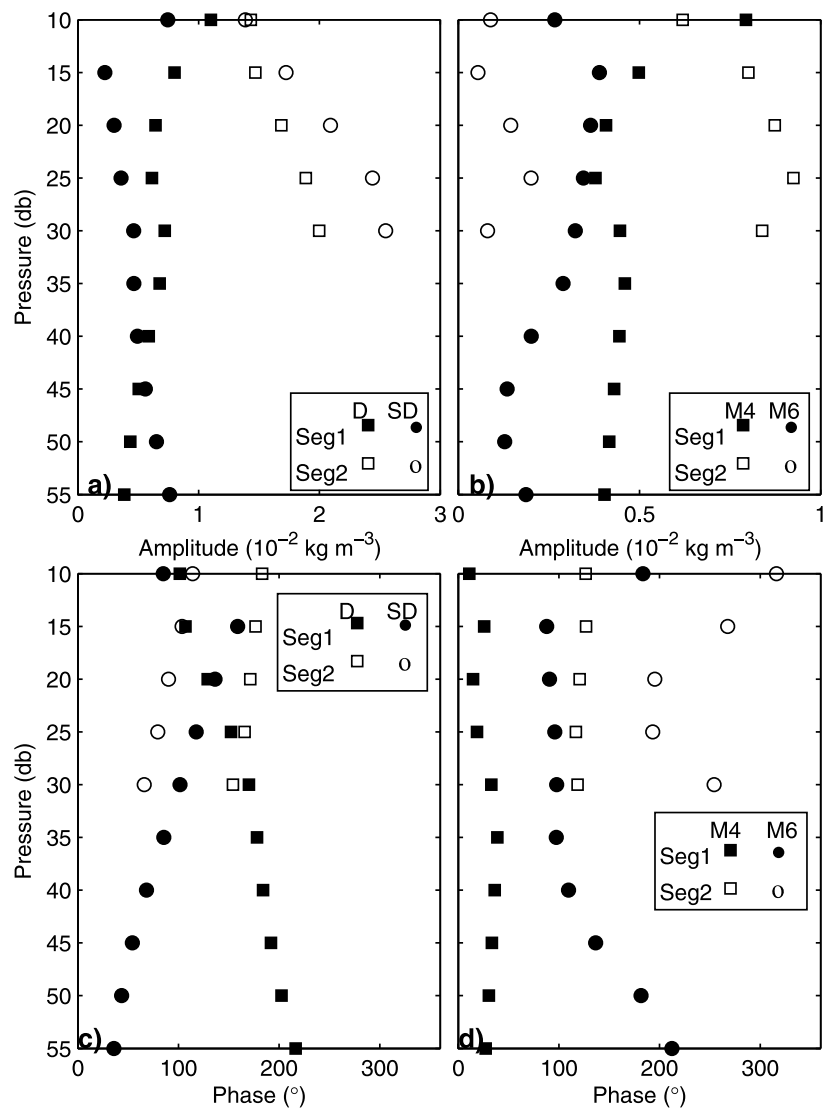

Figure 4. Amplitude of significant tidal constituents: (a) diurnal components (D) and semi-diurnal components (SD), and (b) M4 and M6 from an harmonic analysis of the potential density anomaly for both segments 1 and 2 . (c and d) Same as Figures $4 \mathrm{a}$ and $4 \mathrm{~b}$ but for the phase. 
Table 2. Horizontal and Vertical Wavelength $\lambda$ for $K 1, M 2, S 2$ and $M 6$

\begin{tabular}{|c|c|c|c|c|c|}
\hline \multirow[b]{2}{*}{ Constituents } & \multirow{2}{*}{$\begin{array}{l}\text { Frequency } \\
\text { (cph) }\end{array}$} & \multicolumn{2}{|c|}{$\lambda_{z}(\mathrm{~m})$} & \multicolumn{2}{|c|}{$\lambda_{h}(\mathrm{~km})$} \\
\hline & & Segment 1 & Segment 2 & Segment 1 & Segment 2 \\
\hline K1 & $1 / 23.93$ & 140 & 269 & 4.031 & 7.56 \\
\hline M2 & $1 / 12.42$ & 162 & 150 & 34.135 & 31.4 \\
\hline $\mathrm{S} 2$ & $1 / 12$ & 162 & 150 & 16.942 & 26 \\
\hline M6 (10-25 m) & $3 / 12.42$ & 18 & 29.8 & 1.64 & 0.26 \\
\hline M6 (25-30 m) & & - & 29 & - & 0.257 \\
\hline M6 (35-55 m) & & 59.6 & - & 0.52 & - \\
\hline
\end{tabular}

the semi-diurnal frequencies, the total energy is distributed between M2 and S2 according to the explained barotropic variance. Values of the order of $O(0.1) \mathrm{mW} \mathrm{m}^{-2}$ are obtained. While the diurnal profile has a relative maximum at around $35 \mathrm{~m}$ for segment 1 , and $15 \mathrm{~m}$ for segment 2 , the semi-diurnal baroclinic waves are of similar shape decreasing with increasing depth. Interestingly during segment 1, diurnal and semi-diurnal vertical energy fluxes are of opposite sign while both components are associated with a downward energy flux during segment 2. A relevant quantity easily derived is the vertical derivative of the vertical energy flux. Values up to $0.5 \times 10^{-9} \mathrm{~W} \mathrm{~kg}^{-1}$ are obtained down to $20 \mathrm{~m}$ depth providing evidence of the potential impact of these waves on energy dissipation and mixing.

\subsubsection{Possible Sites of Internal Tide Generation}

[22] The generation of internal tides occurs preferentially in regions where the slope of the bathymetry is equal to that of propagation of internal tide energy, leading to maximum efficiency in the generation process. Following Baines [1986] internal tide generation mostly occurs where the ratio, $\gamma$, between these two slopes is within the interval $[0.5,2]$. In order to identify possible sites of generation in the Storfjorden we computed this ratio, $\gamma$, for the different tidal components

$$
\gamma=\frac{\Delta H / \Delta y}{\alpha},
$$

where

$$
\alpha=\left(\frac{w^{2}-f^{2}}{N^{2}-\omega^{2}}\right)^{\frac{1}{2}}
$$

These maps are displayed in Figure 6 for the tidal components: $O 1, K 1, M 2, S 2$ and $M 6$. Note that the bottom slope has been computed in the direction of maximum ellipse major axis for the diurnal and semi-diurnal frequencies as inferred from AOTIM model (Figure 7).

[23] There are a few spots of $\gamma_{M 6}$ critical values mostly in the center of the basin. This suggests possible generation of $M 6$ internal tides provided that the $M 6$ barotropic tide is significant. Diurnal $\gamma$ values are critical along the west coast, in the center of the basin and to the south of the Edgeøya island. Semi-diurnal $\gamma$ values are critical over most of the Storfjorden except for a few regions in the middle of the basin and south of Edgeøya island. $S 2$ is supercritical and reaches significant amplitude of the order of a few $\mathrm{cm} \mathrm{s}^{-1}$ (Figure 7) with maximum values up to $20 \mathrm{~cm} \mathrm{~s}^{-1}$ south of Edgeøya. Thus significant semi-diurnal tides generated there could propagate into the fjord which is consistent with our observations. The question of baroclinic tides forcing by $M 2$ barotropic tides needs a more detailed investigation since $M 2<f$. As shown by Gerkema and Shrira [2005] non traditional terms become significant for near-inertial waves and one has to consider linear internal wave theory on the non traditional
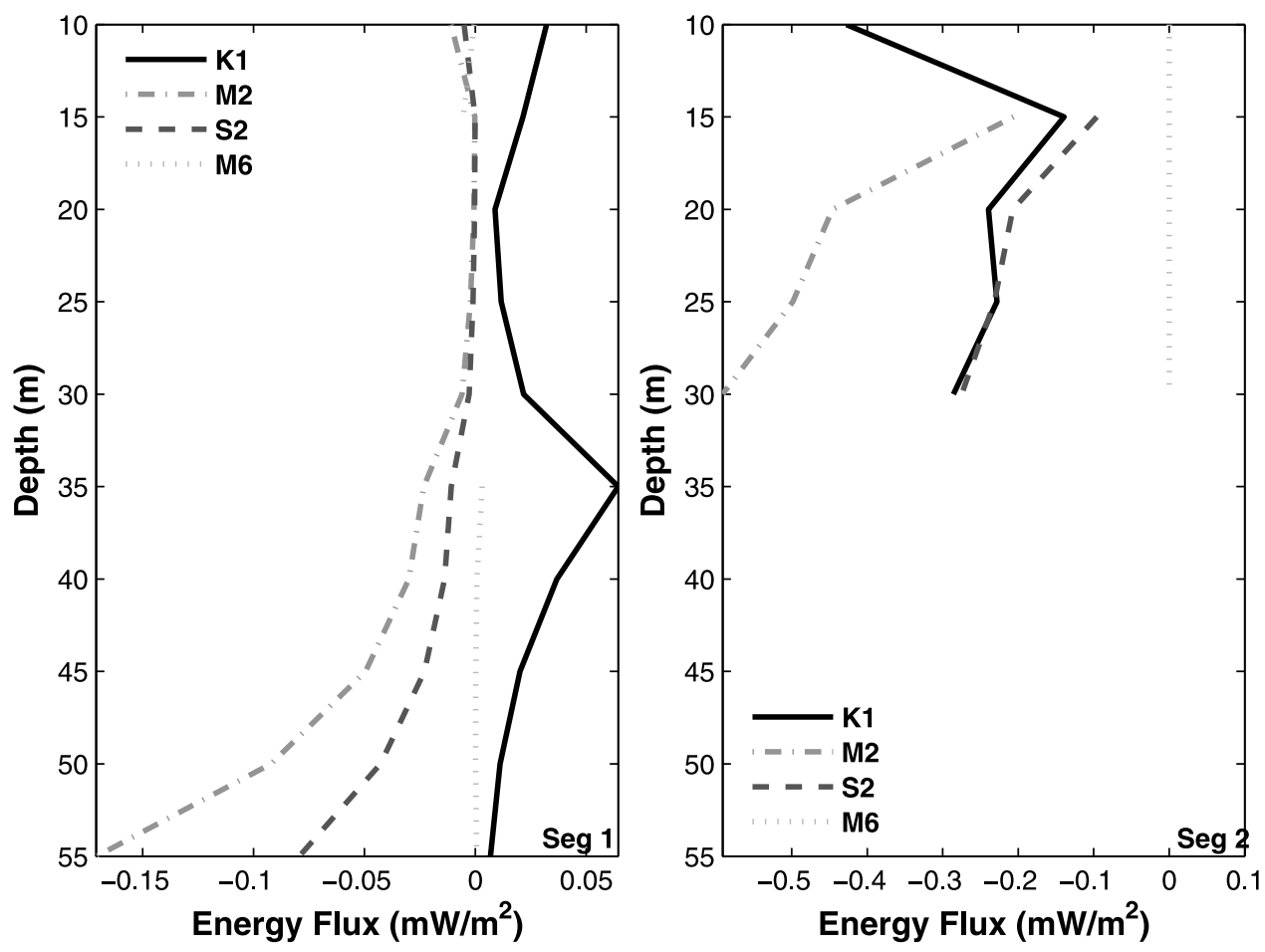

Figure 5. Profiles of vertical energy flux $\left(\mathrm{mW} \mathrm{m}^{-2}\right)$ for $\mathrm{K} 1, \mathrm{M} 2, \mathrm{~S} 2$ and $\mathrm{M} 6$ frequencies for both segments (left) 1 and (right) 2. 


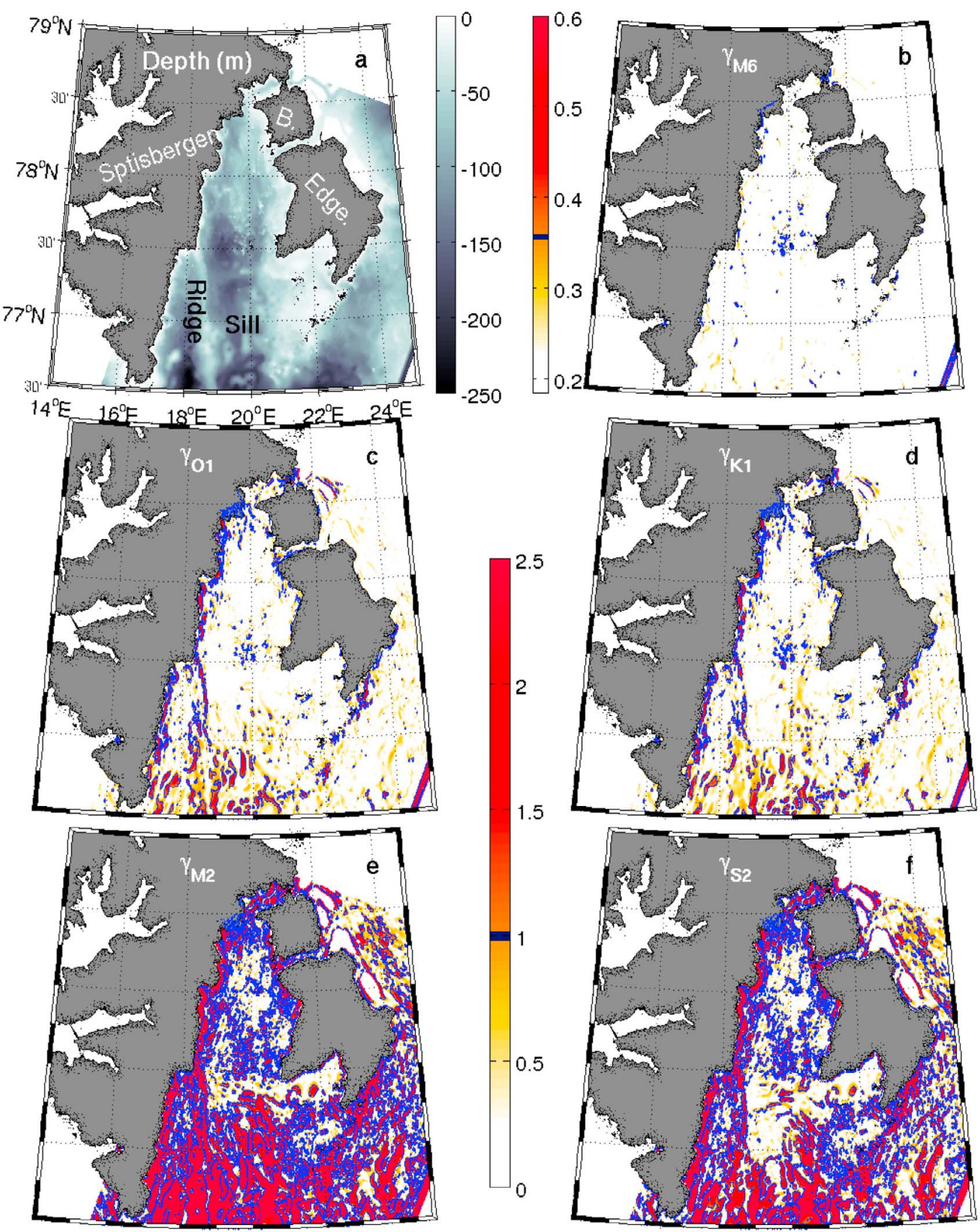

Figure 6. (a) Storfjorden bottom topography from Skogseth et al. [2005b], Spistbergen, Barentsøya (B.) and Edgeøya (Edge.) are identified as well as the sill position. The parameter $\gamma$ is shown for the tidal frequencies of (b) $M 6$, (c) $O 1$, (d) $K 1$, (e) $M 2$, and (f) $S 2$. Note that Figure $6 \mathrm{~b}$ has a distinct color bar. The slope of the topography is computed in the direction of the barotropic tidal current as inferred from AOTIM model (Figures $6 \mathrm{c}-6 \mathrm{f}$ ) while it is inferred from the modulus of the gradient in Figure $6 \mathrm{~b}$.

$\beta$ plane. In this case the frequency domain for internal inertialgravity waves is extended toward sub-inertial frequencies with a minimum value of $\omega_{\min }=f \sqrt{1-0.5\left(f^{2} / N^{2}\right)}$ leading to possible wave trapping within a waveguide of weak stratification. Considering a bottom stratification of about $1 \mathrm{cph}$ $M 2$ is still smaller than $\omega_{\text {min }}$. Thus it appears more likely that forced $M 2$ baroclinic tides could be generated locally with numerous possible sites of generation provided that their distance from the mooring is less than the e-folding scale, of the order of $\lambda_{h} /(2 \pi)=5.4 \mathrm{~km}$ (see Table 2). Another scenario, beyond the scope of the study, would be that of an internal tide generated at lower latitude, for instance near its inertial latitude around bear island, a region of strong generation [Huthnance, 1981], that would have freely propagated up to 

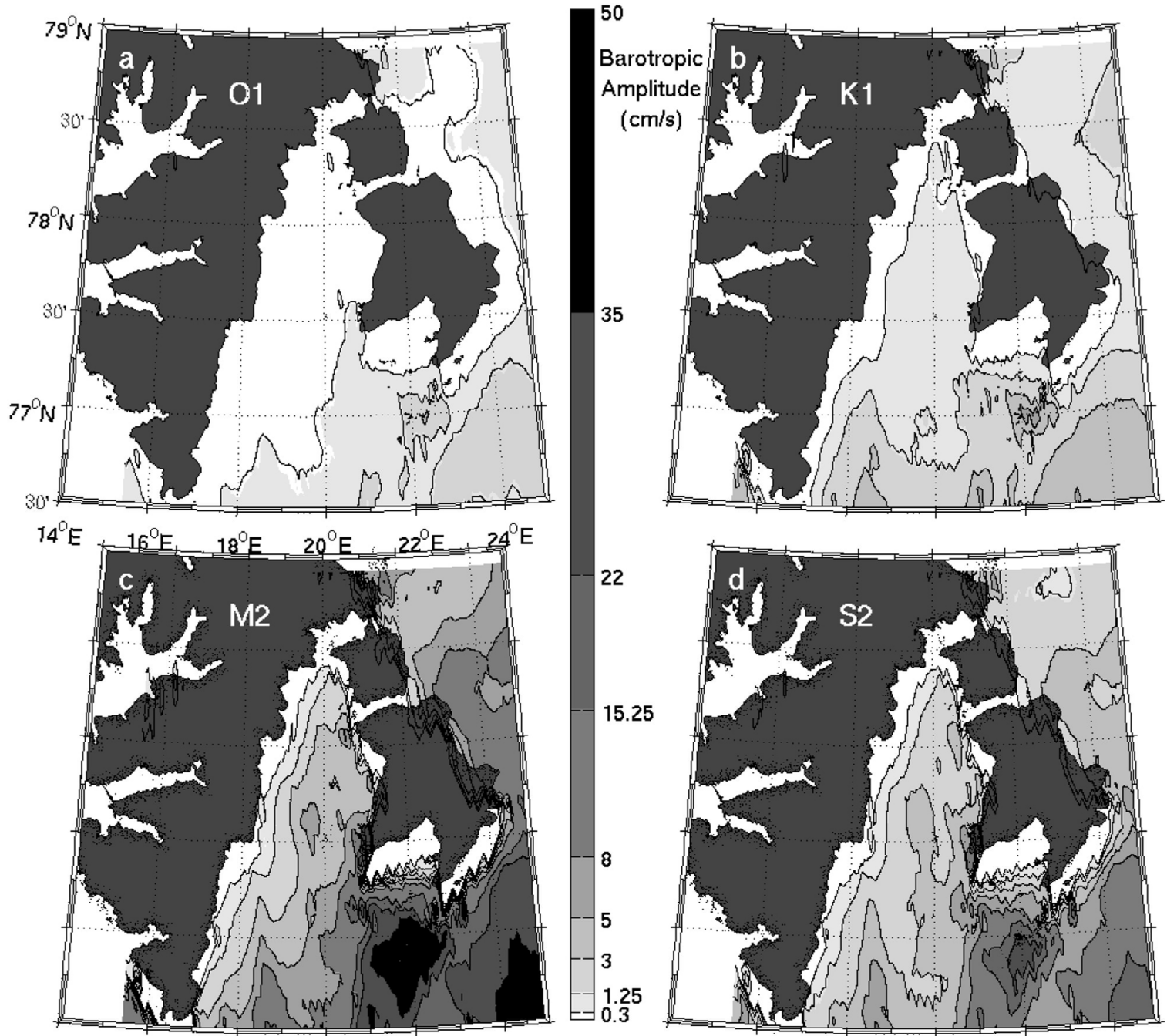

Figure 7. The maximal amplitude for the barotropic current of (a) $O 1$, (b) $K 1$, (c) $M 2$ and (d) $S 2$; obtained from the AOTIM model. The represented isolines correspond to barotropic current amplitudes of $0.3,1.25,3,5,8,2.25,22,35$ and $50 \mathrm{~cm} \mathrm{~s}^{-1}$.

the Storfjorden within a bottom waveguide of weak stratification. This situation could be encountered provided that the bottom stratification is of the order of $0.17 \mathrm{cph}$ which is less than the observed $N$ at the bottom $(\sim 1.5 \mathrm{cph})$.

[24] In contrast the spatial distribution of bottom slopes close to the critical value is very patchy for both diurnal frequencies (O1 and $\mathrm{K} 1)$ with preferential sites for generation in the center of the basin and along the ridge (Figures $6 \mathrm{c}$ and $6 \mathrm{~d}$ ).Owing to the typical e-folding scale for these two components, of the order of $1 \mathrm{~km}$, only waves generated along the ridge could possibly be inferred from our mooring observations. However, the amplitude of both components along the ridge is less than $1 \mathrm{~cm} \mathrm{~s}^{-1}$ thus excluding this hypothesis. Another explanation is that of an internal coastal Kelvin wave that would be generated locally [Støylen and Weber, 2010] and would propagate cyclonically along the Storfjorden shelf. In this case we can infer an e-folding scale and horizontal wavelength along the coast for an internal Kelvin wave of the form $\Phi_{o} \exp \left(-k_{x} x\right) \exp \left(i\left(k_{y} y+k_{z} z-\omega t\right)\right)$ and where $x$ and $y$ are the across-shore and the alongshore coordinates, respectively. The dispersion relation is $\omega=\left(k_{y} / k_{z}\right) N$ and the e-folding length scale in the acrossshore direction is given by $1 / k_{x}$ with $k_{x}=k_{z}(f / N)$ [e.g., Romea and Allen, 1983]. An e-folding length scale of $0.5 \mathrm{~km}$ and $1 \mathrm{~km}$ is obtained for segments 1 and 2, which implies a $\lambda_{h}=2 \pi / k_{y}$ of $6.7 \mathrm{~km}$ and $12.9 \mathrm{~km}$, respectively.

\subsection{Statistical Description}

[25] In this section we characterize the statistical properties of the internal wavefield by comparing the spectra of isopycnal displacements with the Garrett-Munk internal wave spectrum.

\subsubsection{Isopycnal Vertical Displacement}

[26] In a stably stratified fluid, the magnitude of the vertical displacement of water parcels can be computed from the variations of a conservative property of water like temperature, salinity or density. The vertical displacement is generally inferred from the ratio between the deviation from the mean value and the local vertical gradient. This computation, which is derived from a first order expansion of density, however, is only valid for small displacements and for linear stratification (constant vertical gradient). In particular, this 

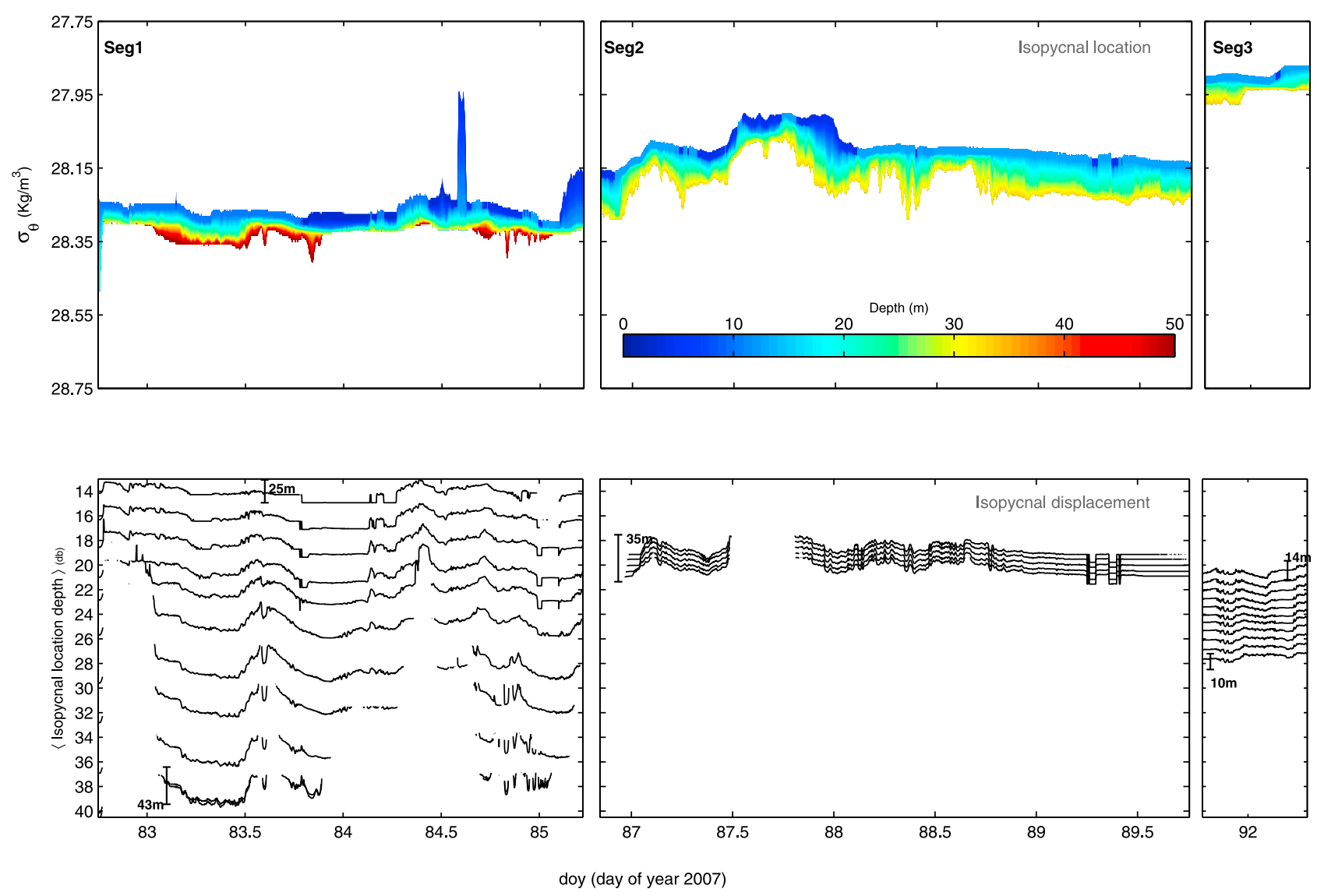

Figure 8. (top) Depth of the isopycnals for segments 1, 2 and 3, respectively, from the minimum to the maximum density value for each segment. (bottom) Time series of isopycnal displacement, $\zeta_{\rho}(\mathrm{m})$. The $\zeta_{\rho}$ shown corresponds to isopycnals from $28.28-28.34$ with $\Delta \rho=0.005 \mathrm{~kg} \mathrm{~m}^{-3}$ for segment 1 , 28.13-28.14 with $\Delta \rho=0.003 \mathrm{~kg} \mathrm{~m}^{-3}$ for segment 2 and 27.92-27.93 with $\Delta \rho=0.001 \mathrm{~kg} \mathrm{~m}^{-3}$ for segment 3. Each $\zeta_{\rho}$ is offset by a factor of 1.2. Each isopycnal time series is displayed at the depth corresponding to the mean depth of the isopycnal. Displacement amplitudes range from [12.75-26.8], [14.37-22.75] and [5.3-7.75] $\mathrm{m}$ for segment 1, 2 and 3, respectively. The range of variations of $\zeta_{\rho}$ is indicated for some of isopycnals.

method does not apply to our data set because of large vertical displacements and a weak stratification (Figure 12a).

[27] We thus implemented a specific method to compute isopycnal displacements in this case of weakly-stratified water column. First, we selected a range of isopycnals that can be tracked throughout the segment. Figure 8 (top) displays the evolution of the water column as MM drifted southward: the water column becomes less dense and the range of isopycnals narrows. More precisely the sigma range for depth down to $30 \mathrm{~m}$ evolved from [27.94 28.32] $\mathrm{kg} \mathrm{m}^{-3}$ for segment 1 to [28.00 28.29] $\mathrm{kg} \mathrm{m}^{-3}$ for segment 2, and to [27.87 27.98] $\mathrm{kg} \mathrm{m}^{-3}$ for the third segment. The densest water masses were observed twice (1) at the bottom $\left(\sim 28.41 \mathrm{~kg} \mathrm{~m}^{-3}\right)$, around day 83.5 and 85 at a mean depth of $55.1 \mathrm{~m}$ and (2) at the surface, during the first $10 \mathrm{~h}$ of measurements where the surface layer reaches high sigma values $\left(\sim 28.48 \mathrm{~kg} \mathrm{~m}^{-3}\right)$ due to an episode of brine release (see F. P. Jardon et al. (Full-depth desalination of Arctic sea ice after the growth season, manuscript in preparation, 2011) for more details). During the second segment, an event of fresher water with a sigma as low as $28.08 \mathrm{~kg} \mathrm{~m}^{-3}$ occurred around day 87.7 down to a depth of $\sim 15 \mathrm{~m}$, while sigmas larger than $28.25 \mathrm{~kg} \mathrm{~m}^{-3}$ were briefly identified at depths larger than $\sim 29 \mathrm{~m}$.

[28] Once the density range was identified, evenly spaced isopycnals were selected (every $0.005,0.003$ and $0.001 \mathrm{~kg} \mathrm{~m}^{-3}$ for segments 1, 2 and 3, respectively) and subsequently the depth of selected isopycnal surfaces were determined (Figure 8, top). Eventually, time series of isopycnal vertical displacements were obtained by removing the average depth of the given isopycnal surface. The longest available time series of vertical displacement were selected to compute frequency spectra. An overview of the time evolution of isopycnal displacements is shown in Figure 8 (bottom). Largest displacements are encountered during segment 1 in the regions of weaker stratification with displacement reaching $\pm 27 \mathrm{~m}$ at a depth of $41 \mathrm{~m}$, while smallest values are encountered during segment 3 at depths of about $20 \mathrm{~m}$. In order to characterize the variability of the internal wavefield, frequency spectra of vertical displacement were calculated (Figure 9) for each segment at different depths. These spectra were next compared with the Garrett-Munk internal wave model which is briefly introduced. 

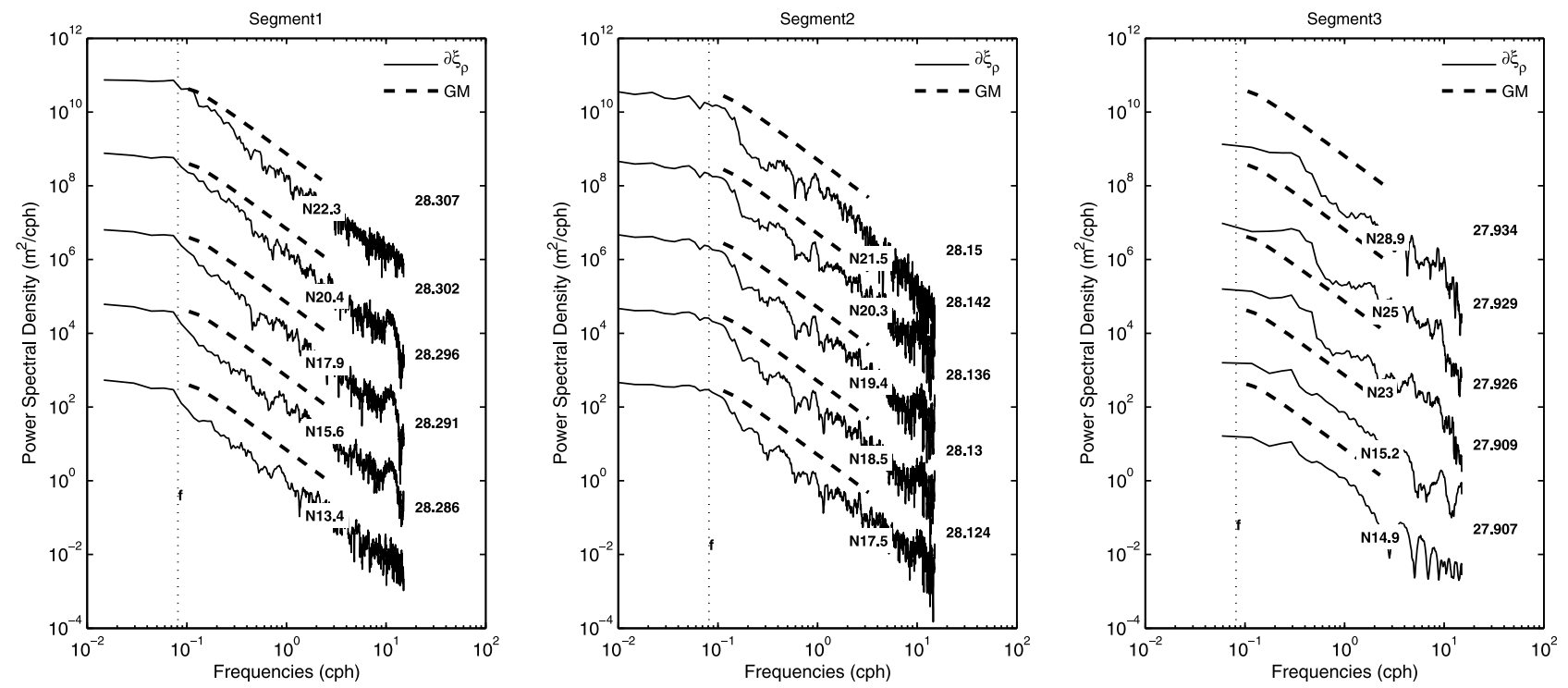

Figure 9. Spectra of selected isopycnals displacement for segments (left) 1, (middle) 2 and (right) 3. The Garrett-Munk spectrum is also shown (dashed line), based on a mean buoyancy frequency value. The isopycnal references, the average depth of isopycnal and the average buoyancy frequency are indicated. Spectra are offset by a factor 100 .

\subsubsection{Garrett and Munk Internal Wave Model}

[29] The Garrett-Munk internal wave model (GM) [Garrett and Munk, 1972, 1975], which provides a statistical description of the internal wavefield, has been derived empirically from observations at different locations in the world's oceans. This model is based on the assumption that the internal wavefield which is in steady state can be represented as a random combination of linear internal waves with random phases. Also the internal wave energy distribution is assumed to be isotropic in the horizontal direction. Here we used the formulation of the spectrum presented by Munk [1981] for vertical displacement

$$
F_{\zeta}(\omega)=\frac{2}{\pi} \frac{f}{N} E_{o} b^{2} N_{o} \frac{\left(\omega^{2}-f^{2}\right)^{\frac{1}{2}}}{\omega^{3}},
$$

where $\mathrm{E}_{o}=6.3 \times 10^{-5}$ is the GM nondimensional energy level, $\mathrm{b}=1300 \mathrm{~m}$ and $\mathrm{N}_{o}=3 \mathrm{cph}$ are the vertical scale depth and amplitude of the mean exponential buoyancy frequency profile: $N=N_{0} \exp (-z / b)$. Then, the vertical displacement spectrum depends on the local values of the buoyancy frequency $\mathrm{N}$ and the inertial frequency $f$. The value of $\mathrm{N}$ was chosen for each depth as the time average for each segment, namely $2 \mathrm{cph}$ for segment $1,2.5 \mathrm{cph}$ for segment 2 and $2.2 \mathrm{cph}$ for segment 3 .

[30] Observed frequency spectra were found to be consistent with the GM empirical model (Figure 9). The shape of the spectra is close to that of GM: similar slope values with slight variations as a function of time and depth. For instance, spectra slopes are depth-dependent for segment 1 ranging from -1.91 to -2.28 between $13.4-22.3 \mathrm{~m}$. Note that in all cases they remain close to the GM value. Instead slopes obtained for segment 3 significantly differ from the GM model.

[31] The variance of the isopycnal displacement within the internal wave frequency band was next computed and compared with that of the GM model. Another criterion was also applied, following previous works. Indeed an independent parameter " $r$ " which gathers three of the canonical GM model parameters [Desaubies, 1976] was defined and estimated for internal wave observations in the Arctic region [Levine et al., 1985; Plueddemann, 1992]

$$
r=E_{o} b^{2} N_{o}
$$

to compare spectral levels. Then, using (7) and (6) the vertical displacement spectra, and hence the total energy, are scaled by the $r$-parameter. This parameter was obtained by fitting the vertical displacement spectra (Figure 9 and equation (8)) to the GM spectral shape (9) in a least squares sense, then assuming that isopycnal vertical displacement spectra can be written as

$$
F_{\zeta W}(\omega)=r_{I W} x(\omega)+c
$$

with

$$
x(\omega)=\frac{2}{\pi} \frac{f}{N} \frac{\left(\omega^{2}-f^{2}\right)^{\frac{1}{2}}}{\omega^{3}}
$$

the r-parameter corresponding to the observed data $\left(r_{I W}\right)$ is obtained.

[32] Note that if the GM model were an appropriate representation of the internal wavefield in any ocean-condition, both the variance ratio and the r-parameter would be constant, equal to 1 , at any depth. Both ratios as function of depth are displayed in Figure 10. We found that observed spectral levels in Storfjorden region are lower than GM energy level by a factor of $0.026-0.7$ and by a factor of 0.04-0.55 for r-parameter and variance, respectively. The best agreement is found for segment 2 for which high frequency oscillations were observed. This ratio also varies 


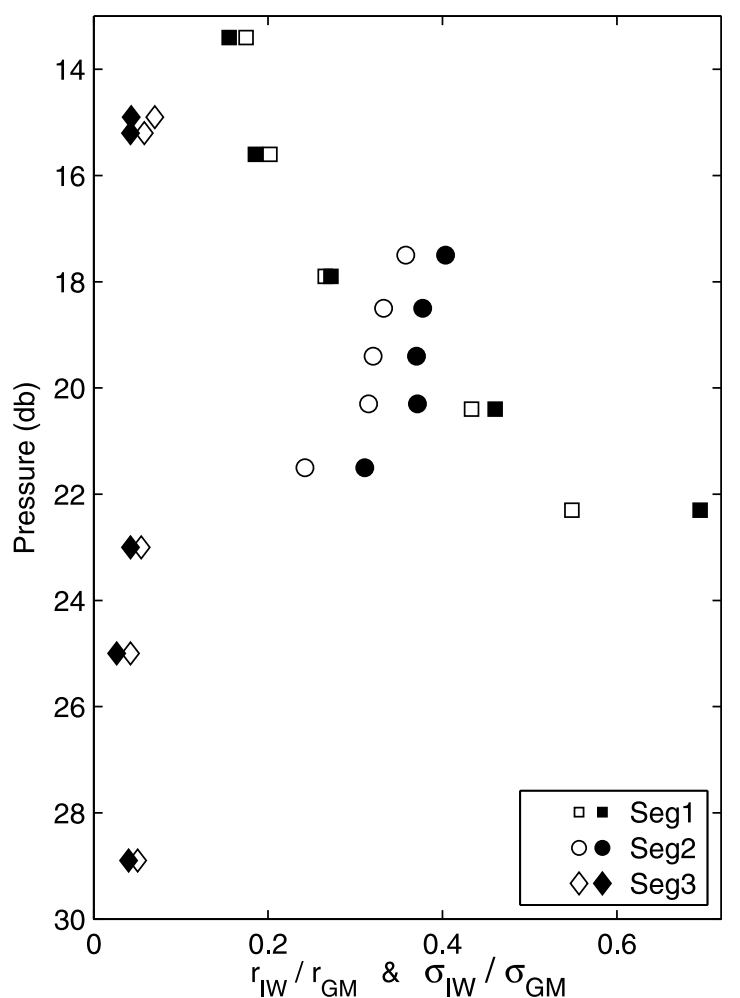

Figure 10. Profiles of dimensionless estimates of the spectral level, computed as a variance-ratio $\sigma_{I W}^{2} / \sigma_{G M}^{2}$ (empty markers) and as r-ratio $r_{I W} / r_{G M}$ between observations and the GM model.

with depth ranging from 1.56 to 0.67 between 13.4 to $23.3 \mathrm{~m}$ depth during this time interval.

\section{Energy Dissipation and Turbulent Mixing}

\subsection{Methods Used to Estimate Kinetic Energy Dissipation}

[33] Energy dissipation is classically inferred from hydrographic and current measurements at fine vertical scales using the so-called "fine scale parameterizations" [e.g., Wijesekera et al., 1993; Polzin et al., 1995]. In these parameterizations energy dissipation is deduced from the internal wavefield assuming that wave-wave interactions are responsible for the onset of turbulence since they initiate the energy transfers toward small scales leading to instabilities and wave breaking. Note that energy transfers differ when a low frequency mode dominates in which case there is a direct transfer to small dissipative scales through shear instability. This dynamical situation was encountered by MacKinnon and Gregg [2003] who proposed a parameterization specific to this case. The dynamics in the Storfjorden is characteristic of the former case with a set of internal wave components at different frequencies. We therefore estimate energy dissipation based on the MacKinnon and Gregg [2005] formulation which is established on results from wave-wave interaction theory [Henyey et al., 1986] with slight modifications by Gregg [1989] and Polzin et al. [1995]

$$
\varepsilon=1.8 \times 10^{-6}\left[f \cosh ^{-1}\left(\frac{N_{o}}{f}\right)\right]\left(\frac{S_{10}^{4}}{S_{G M}^{4}}\right)\left(\frac{N^{2}}{N_{o}^{2}}\right),
$$

where $f$ is the coriolis frequency, $\mathrm{N}_{o}=3 \mathrm{cph}$ is the canonical GM buoyancy frequency value, and $S_{10} / S_{G M}$ is the ratio between the computed shear variance at $10 \mathrm{~m}$ and the Garrett and Munk estimate of the shear variance. Note that this parameterization was initially formulated in terms of the internal wave energy, $E_{I W}$, and next expressed in terms of shear variance or shear variance square [Gregg, 1989], provided that $\left\langle S_{10}^{2}\right\rangle / S_{G M}^{2}=E_{I W} / E_{G M}$. Here we use the formulation in terms of energy, which is more appropriate to our data set. More precisely we estimate $\varepsilon$ from the ratio between the potential energy of the internal wavefield and that of the GM model in the absence of current measurements

$$
\varepsilon=1.8 \times 10^{-6}\left[f \cosh ^{-1}\left(\frac{N_{o}}{f}\right)\right]\left(\frac{\left\langle P E_{I W}\right\rangle^{2}}{P E_{G M}^{2}}\right)\left(\frac{N^{2}}{N_{o}^{2}}\right),
$$

where

$$
P E_{G M}=\frac{53}{2} N^{2}\left(\frac{N}{N_{o}}\right)^{-1}
$$

is the Garrett-Munk available potential energy and $\left\langle P E_{I W}\right\rangle=$ $0.5 N^{2} \zeta^{2}$ is the measured available potential energy from isopycnal vertical displacement $(\zeta)$, where angle brackets denote a 3 h-running mean. Kinetic energy dissipation rate is thus a function of internal wave energy $\left\langle E_{I W}\right\rangle^{2}$ and stratification.

[34] In order to test the sensitivity of the model, we estimated the difference between the classical formulation of $\varepsilon$ in terms of total energy and that proposed here in terms of potential energy. To this aim we computed the total energy assuming that the dynamics of internal waves are linear so that polarization relations do apply (see equation (3)). Note that this estimate is fairly sensitive since kinetic energy diverges close to $f$ as potential energy is never exactly zero. However, we found a generally good agreement between the two estimates, typically within a factor of 3 . In addition the method was tested against direct estimates of $\varepsilon$ based on Thorpe scales using repeated CTD profiles performed over 13 hours during the recovery of the moorings. A good agreement was obtained as detailed in Appendix A which provides a validation of this method for our data set.

[35] Note that the previous method applies only in statically stable regions since available potential energy can not be computed within overturning events for which isopycnal displacements are not uniquely defined. In these regions an expression for $\epsilon$ based on the statistical relationship between Thorpe [Thorpe, 1977] scale and Ozmidov scale, $\varepsilon=0.64 L_{T}^{2} N^{3}$, has been derived by Dillon [1982]. This method is applied here by assuming that the Thorpe scale is equal to the vertical extent of the overturning, thus giving an upper bound to the dissipation in the overturning regions.

\subsection{Formulations for Diapyenal Diffusivity}

[36] The rate of cross-isopycnal turbulent mixing or diapycnal diffusivity, $\left(\mathrm{K}_{\rho}\right)$ is commonly inferred from the kinetic energy dissipation using the Osborn [1980] relationship

$$
K_{\rho}=\frac{\Gamma \varepsilon}{N^{2}},
$$



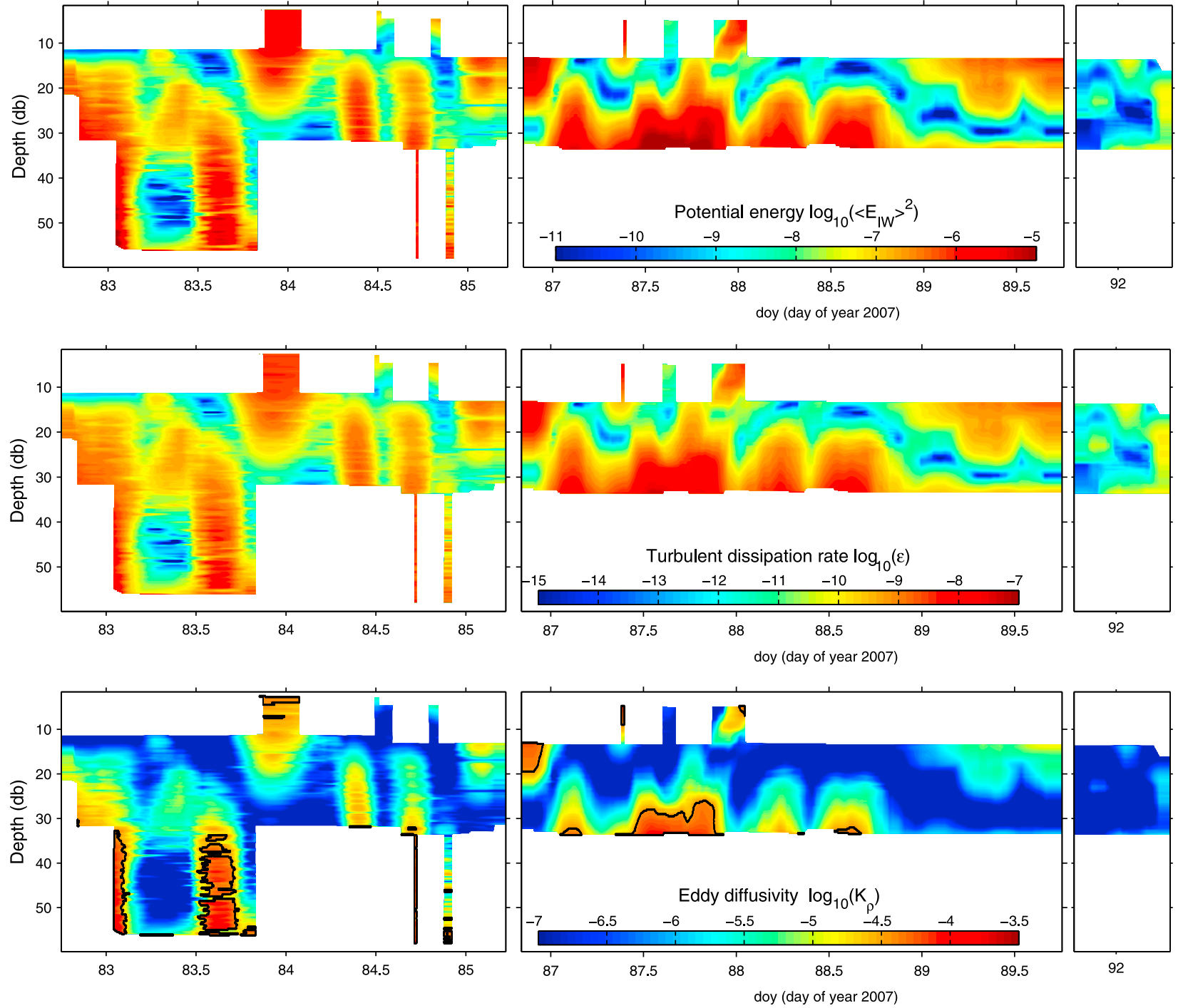

Figure 11. Time-depth plots of the 3h-running mean of (top) potential energy ([m $\left.\mathrm{s}^{-2}\right]$ ), (middle) dissipation of turbulent energy per unit mass $\left(\varepsilon\left[\mathrm{W} \mathrm{kg}^{-1}\right]\right)$ and (bottom) vertical diffusivity $\left(K_{\rho}\left[\mathrm{m}^{2} \mathrm{~s}^{-1}\right]\right)$, using Shih's model (see equation (14)) when $\varepsilon / \nu N^{2}>100$ and Osborn's model (equation (13)) elsewhere. The isoline of turbulence activity parameter equal to 100 is indicated in black.

where $\Gamma$ is a mixing efficiency. Mixing efficiency is related to the flux Richardson number, $R_{f}\left(\Gamma=R_{f}\left(1-R_{f}\right)\right)$ defined as the ratio between buoyancy flux and turbulent production. Typically $\Gamma=0.2$ which corresponds to the critical flux Richardson number $R_{f}^{\text {crit }}=0.17$ obtained for a steady state [Osborn, 1980].

[37] Recently, the application of the Osborn model (equation (13)) to flows undergoing large variations in turbulence intensity and therefore high variation of $R_{f}$, has been investigated by Barry et al. [2001] and Shih et al. [2005]. The turbulence intensity is characterized by the parameter $\varepsilon / \nu N^{2}$ [Ivey et al., 2008] which can be interpreted as the ratio between destabilizing effects of turbulence and stabilizing effects resulting from the combined action of buoyancy and viscosity. Buoyancy effects are inefficient at stabilizing turbulence when turbulence develops on a faster time scale which occurs for high values of this parameter, typically $\varepsilon / \nu N^{2}$ greater than 100 . Shih et al. [2005] showed that the Osborn model overestimates $K_{\rho}$ by a factor of 2 for these intense turbulent regimes and proposed a new parameterization for these regimes

$$
K_{\rho}=\nu\left(\frac{\varepsilon}{\nu N^{2}}\right)^{\frac{1}{2}}
$$

with the kinematic viscosity, $\nu=1.9 \times 10^{-6} \mathrm{~m}^{2} \mathrm{~s}^{-1}$. Hence, taken into account these results, the formulation of $K_{\rho}$ from Shih et al. [2005] (equation (14)) is applied here when $\varepsilon /\left(\nu N^{2}\right)>100$ while the Osborn model is applied for turbulent regimes of intermediate turbulence intensity $(7<\varepsilon$ l $\left.\left(\nu N^{2}\right)<100\right)$.

\subsection{Estimates of Energy Dissipation and Diapyenal Mixing}

[38] Time depth evolution of kinetic energy dissipation, $\epsilon$, and diapycnal diffusivity, $K_{z}$, inferred from fine-scale parameterization is displayed in Figure 11. 

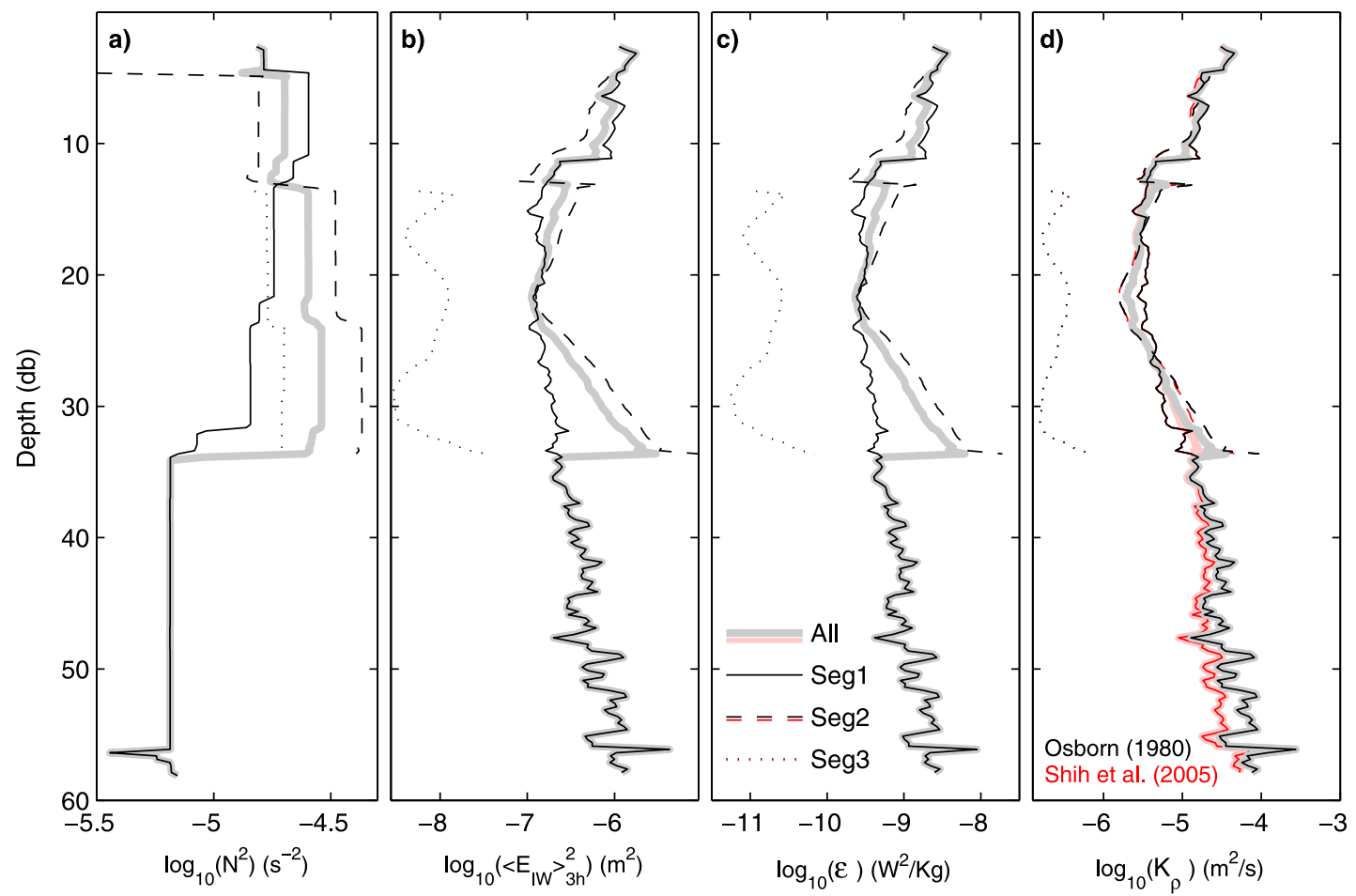

Figure 12. Averaged vertical profiles of (a) buoyancy frequency $\left(N^{2},\left[\mathrm{~s}^{-2}\right]\right)$; (b) potential energy $\left(\left\langle E_{I W}^{2}\right\rangle\right.$, $\left.\left[\mathrm{m}^{2} \mathrm{~s}^{-2}\right]\right)$; (c) turbulent dissipation $\left(\varepsilon,\left[\mathrm{W} \mathrm{kg}^{-1}\right]\right)$ and (d) vertical diffusivity $\left(K_{\rho},\left[\mathrm{m}^{2} \mathrm{~s}^{-1}\right]\right)$ for the entire time series and for each segment separately (identified by different line styles, see legend in Figure 12c). Depending on turbulent activity parameter values $\left(\varepsilon / \nu N^{2}>100\right)$ both parameterizations are computed (Osborn [1980], black lines and Shih et al. [2005], red lines).

[39] $\epsilon$ varies within a wide range of values, typically within $\left[10^{-12}, 10^{-7}\right] \mathrm{m}^{2} \mathrm{~s}^{-3}$. The general pattern of $\epsilon$ follows that of the available potential energy squared (Figure 11, top) which reflects the fact that the background stratification varies weakly. Spots of high energy dissipation are encountered over all the resolved interval during segment 1 , from $5 \mathrm{~m}$ depth down to $55 \mathrm{~m}$ depth, and this distribution can be correlated with the vertical profile of the amplitude of the semi-diurnal and M4 and M6 tidal components. During segment 2 the calculation of $\epsilon$ was only possible within $[10,30] \mathrm{m}$ and the spots of high values can be correlated with the diurnal and semi-diurnal tidal components.

[40] Diapycnal diffusivity values range from molecular diffusivity $\left(\sim 1.3 \times 10^{-7} \mathrm{~m}^{2} \mathrm{~s}^{-1}\right)$ to $2.8 \times 10^{-4} \mathrm{~m}^{2} \mathrm{~s}^{-1}$. The highest values are reached near the sea ice interface and near the bottom while minimum values are observed between $\sim 12-30 \mathrm{~m}$, within the pycnocline.

[41] Mean vertical profiles of $\left\langle E_{I W}\right\rangle, \varepsilon, N$ and $K_{\rho}$ are displayed in Figure 12. Near surface and near bottom intensification of energy dissipation and diapycnal mixing is retrieved in the first two segments with a value of $K_{z}(\sim 5.3 \times$ $\left.10^{-5} \mathrm{~m}^{2} \mathrm{~s}^{-1}\right)$ near the surface and around the same value at depth.

[42] A comparison between the Osborn and Shih models is shown as well. Diapycnal diffusivity differs at depth for the most turbulent regimes encountered below $35 \mathrm{~m}$ in the weakly stratified waters. The Osborn model overestimates diapycnal diffusivity with values of $1.2 \times 10^{-5}-2.7 \times 10^{-4} \mathrm{~m}^{2} \mathrm{~s}^{-1}$ to be compared with values of $0.9 \times 10^{-5}-0.7 \times 10^{-4} \mathrm{~m}^{2} \mathrm{~s}^{-1}$ for Shih's model.
[43] In contrast in statically unstable regions both $\varepsilon$ and $K_{\rho}$ are at least one order of magnitude greater than those inferred in statically stable regions from fine scale parameterization (see Figure 13). In fact, dissipation rate and eddy diffusivity can reach values up to $\sim 10^{-5} \mathrm{~W} \mathrm{~kg}^{-1}$ and $\sim 10^{-3} \mathrm{~m}^{2} \mathrm{~s}^{-1}$ as is observed below the ice during the first $20 \mathrm{~h}$ of measurements. This intense mixing event quite likely results from a brine release episode that was evidenced at the same time (Jardon et al., manuscript in preparation, 2011).

[44] In conclusion these estimates gave evidence of two layers of enhanced energy dissipation and diapycnal mixing. Brine release leads to the strongest dissipation event with a weaker contribution of internal waves. As these waves are continuously forced by tides, however, their impact on the stratification can be significant as well when considered over a longer timescale.

\subsection{Heat Flux Resulting From Diapycnal Mixing and Impact on Local Heating/Cooling Rates}

[45] In order to have a more quantitative idea of the impact of diapycnal mixing, we computed the vertical heat flux using the diapycnal eddy diffusivity $K_{z}$ inferred from fine-scale parameterization: $Q=\rho c_{p} K_{z} \frac{\partial T}{\partial z}$. A net downward heat flux is obtained with values of about $0.2 \mathrm{~W} \mathrm{~m}^{-2}$. The local change in temperature was next evaluated, $\frac{1}{\rho c_{p}} \partial_{z} Q$, and is displayed in Figure 14. During segment 1 a local cooling is observed around $0.025^{\circ}$ month $^{-1}$ in the upper layer, while the situation is more complex at depth with layers of alternating heating and cooling. The latter results from variations in eddy diffusivity leading to regions of convergence and 
(a) (b)

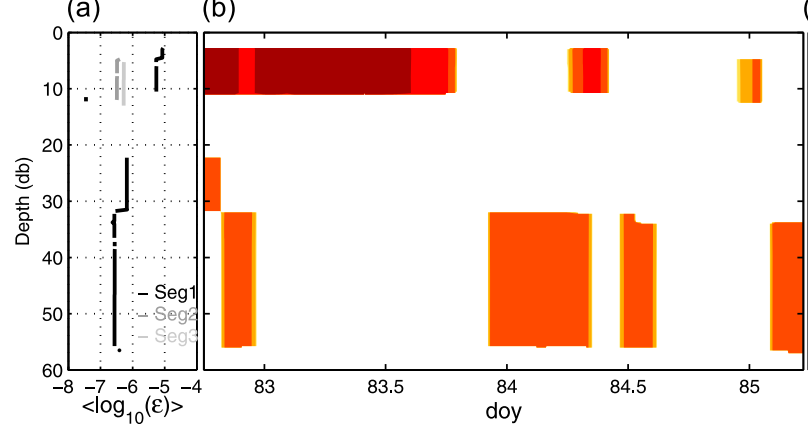

(c)

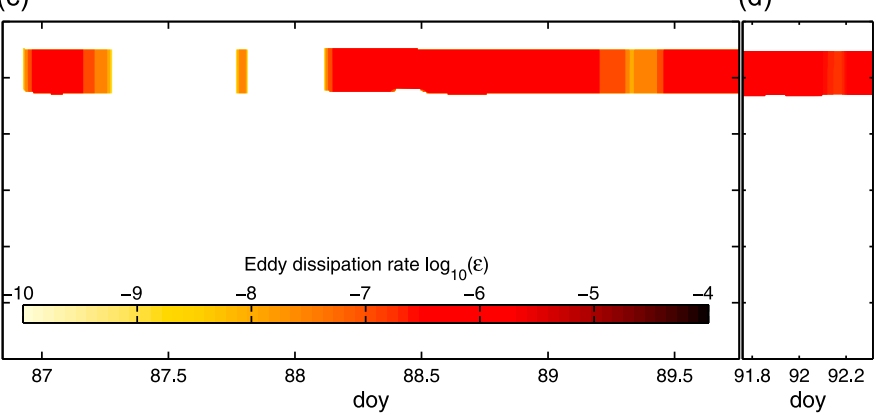

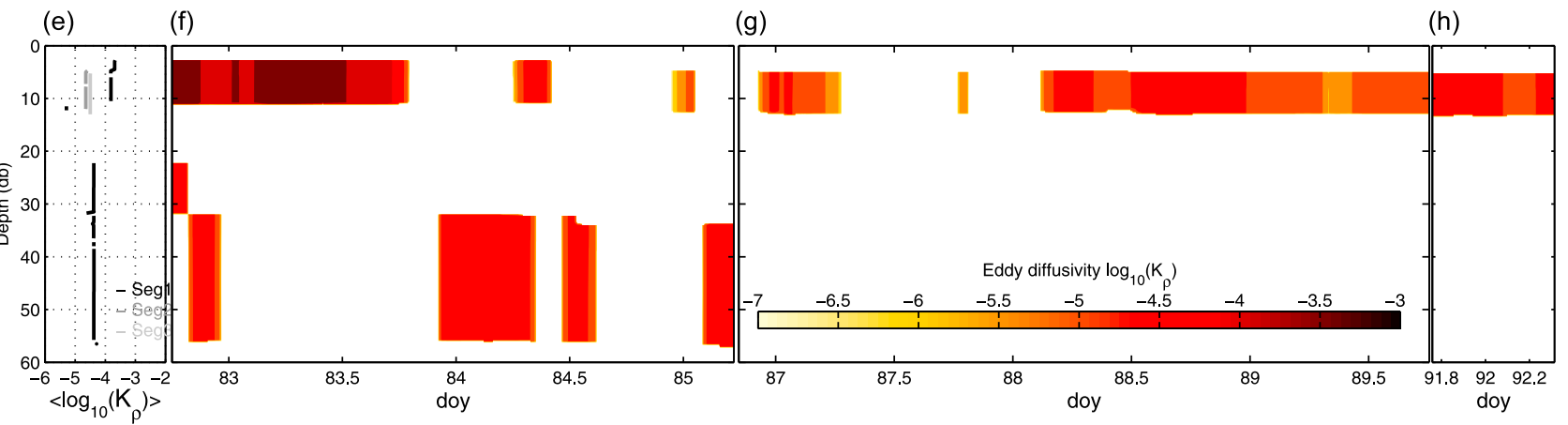

Figure 13. Vertical profile of (a) $\varepsilon$ and (e) $K_{\rho}$ for each segment. Time-depth plots and of the 3 h-running mean of turbulent vertical (b-d) dissipation $\left(\varepsilon\left[\mathrm{W} \mathrm{kg}^{-1}\right]\right)$ and $(\mathrm{f}-\mathrm{h})$ diffusivity $\left(K_{\rho}\left[\mathrm{m}^{2} \mathrm{~s}^{-1}\right]\right)$, from the Thorpe scale in unstable areas.

divergence of the heat flux. The net effect is a local heating in the lower layer. During segment 2, diffusive heat fluxes lead to a local cooling at mid-depth in the pycnocline, which could be due to breaking internal waves, upwelling cooler waters. There is a complex pattern of local heating and cooling regions that would need to be investigated over longer time series to estimate this impact. The values of $O$ $\left(10^{-2}\right)^{\circ}$ month $^{-1}$ that are inferred, however, suggest that this effect could be significant.

\section{Summary and Discussion}

[46] The dynamics of high frequency internal waves were characterized from observations collected by a drifting mooring in March 2007 in the Western part of Storfjorden. At diurnal and super diurnal frequencies tides and baroclinic waves dominate. After a characterization of this wavefield and potential energy sources for these baroclinic waves, we provided estimates of diapycnal mixing.

[47] Barotropic tides were first characterized from bottom pressure measurements during almost one lunar cycle. Semi-diurnal tides $(M 2$ and $S 2)$ were identified as the main contributors accounting for $80.6 \%$ of the total variance with amplitudes around 27 and $16.5 \mathrm{~cm}$. The baroclinic component was then inferred from density fluctuations. We found vertical propagation at the different tidal periods, namely diurnal, semi-diurnal and quarter-diurnal periods. This suggests the possibility of local generation of baroclinic tides. To test this hypothesis, we computed the ratio between the bottom slope and the direction of energy propagation of the different baroclinic wave components. We found numerous regions of bathymetry with slope close to the critical value for both semi-diurnal and quarter-diurnal frequencies. So tides

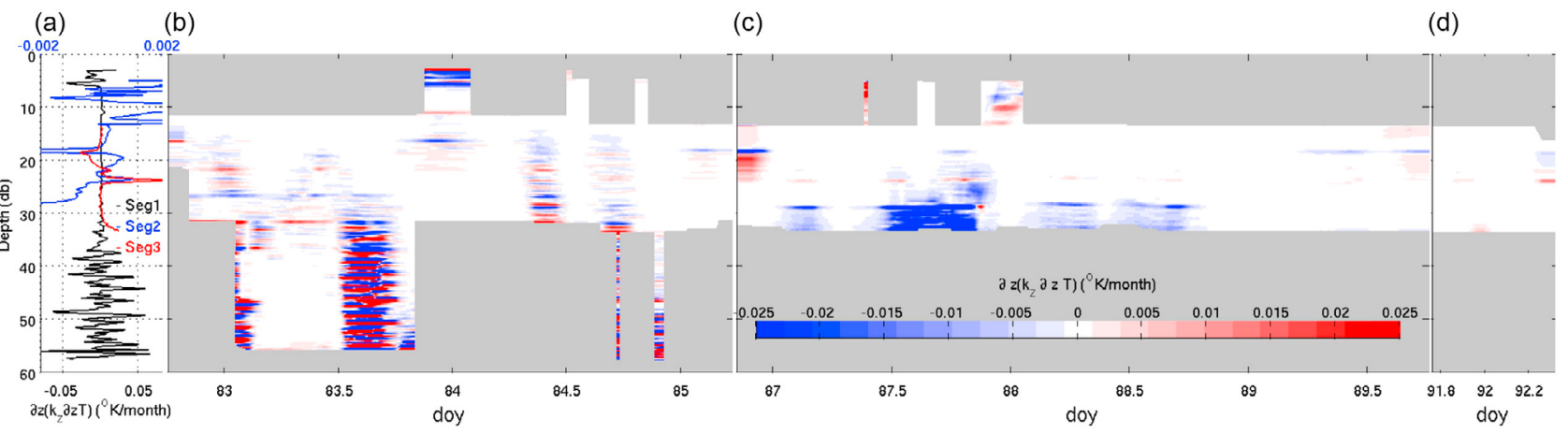

Figure 14. (a) Mean vertical profile of the local heating/cooling rate averaged over each segment, and (b-d) local heating/cooling rate as a function of time and depth for segments 1 and 2. 
indeed can act as a source for baroclinic waves in coastal areas of the Storfjorden. While these waves can propagate freely as internal gravity waves, for both the quarter-diurnal and semi-diurnal S2 periods, their nature necessarily differs for semi-diurnal $M 2$ and diurnal periods, since their frequency is sub-inertial. In some cases, when the effective inertial frequency is slightly sub-inertial due to the relative vorticity field [e.g., Kunze, 1985], these waves can propagate freely provided that the frequency of the waves is larger than the effective inertial frequency. This could be the case here for the semi-diurnal component. Evidence of baroclinic tidal signal was highlighted by Fer et al. [2003] southward in Storfjorden at the sill. An hypothesis, would be that these baroclinic tides generated at the sill would then propagate into the fjord. Alternatively these semi-diurnal waves could be forced locally and decay with an e-folding scale of a few $\mathrm{km}$. The case of baroclinic diurnal oscillations is somehow different since the frequency is far too sub-inertial for internal inertial-gravity waves. In this case previous works suggest that internal Kelvin waves and topographic shelf waves can be excited by diurnal tides. The Yermak Plateau is a wellknown area for its strong diurnal oscillations [e.g., Padman et al., 1992; Fer and Geyer, submitted manuscript, 2009] and its implications in enhancing diapycnal mixing rates. Similar processes could occur in the Storfjorden as suggested by the intensification of diurnal oscillations at depth but further observations are required to confirm this hypothesis.

[48] Having identified the role of tides as potential source of internal waves, we characterized the internal wavefield in comparison with the Garrett-Munk model. For each segment, we observed energy levels below the canonical GM energy level due to different behavior. While energy levels of segments 2 and 3 were fairly depth-independent and lower than GM by a factor of 0.37 and 0.04 , respectively, energy levels of segment 1 increased considerably with depth up to $\sim 0.7$ times the GM energy level. This increase during segment 1 can be correlated with that of the explained variance of internal tides that reaches its maximum value (not shown), at around the same depth. During segment 2, the highest energy level and the best spectral fit with the GM model can be related with the mesoscale eddy field, with a cyclonic filament observed on satellite images. This suggests that this structure could contribute to the local generation of internal waves. These results compare well with the contrasting situations encountered in the Arctic. Indeed, in most cases the internal wave energy level is lower compared to lower-latitude observations with values typically 3 to 70 times lower than the GM level [Levine, 1990; Levine et al., $1987,1985]$. However, in a few instances, the internal wavefield can reach energy levels comparable to those of midlatitudes: in the vicinity of topographic sources [Plueddemann, 1992] as well as in the presence of mesoscale eddies or filaments from which the internal wavefield can extract energy [Levine et al., 1987]. These two instances are encountered here during the first two segments. Thus the Storfjorden appears to be a place gathering different internal wave sources and it is not surprising to find spectral levels comparable with GM. Moreover, the physical configuration of the Storfjorden, a semi-enclosed basin of small horizontal dimensions, favors the trapping of internal wave energy.

[49] The impact of internal waves on mixing was next examined. Dissipation was estimated using a fine-scale parame- terization based on wave-wave interaction theory [e.g., Henyey et al., 1986; Gregg, 1989; MacKinnon and Gregg, 2005]. In this parameterization, valid for an internal wavefield close to the GM model, dissipation is related to the relative energy density or velocity shear variance compared to canonical values (GM model). The good agreement between the experimental spectra and the GM model found in this study gives confidence that such a parameterization can be applied here. The application of the method was also confirmed by a comparison with direct estimates of dissipation from Thorpe scales using a 6-hour CTD station at a different time but in the same location (see Appendix A).

[50] The question of the relationship between eddy diffusivity, $K_{\rho}$, and energy dissipation, $\varepsilon$, as a function of turbulence intensity was next addressed in light of recent work. [e.g., Barry et al., 2001; Shih et al., 2005] showed that this relationship depends on the energetics of the stratified turbulent flow which can be easily characterized by the dimensionless parameter, $\varepsilon / \nu N^{2}$. Thus they identified different power laws for $K_{\rho}$ as a function of $\varepsilon$ for intermediate and intense turbulent regimes. Accordingly, turbulent diffusivity coefficient $K_{\rho}$ was inferred from the energy dissipation using different formulations depending on $\varepsilon / \nu N^{2}$ following Shih et al. [2005]. Note that the application of the Osborn method would have lead to an over estimate of $K_{\rho}$ by a factor of 6 for $6 \%$ of the data that correspond to the energetic regime.

[51] Time averaged vertical profiles of turbulent dissipation and diffusivity coefficients (Figure 12) revealed maximal values near the surface and near the bottom and minimum values around $21 \mathrm{~m}$ depth $\left(\varepsilon O\left(10^{-8}\right) \mathrm{W} \mathrm{kg}^{-1}\right.$ and $\left.K_{\rho} O\left(10^{-4}\right) \mathrm{m}^{2} \mathrm{~s}^{-1}\right)$. These estimates are consistent with microstructure measurements by Fer et al. [2004] leading to $\mathrm{K}_{z}$ of the order of $O\left(10^{-4}\right) \mathrm{m}^{2} \mathrm{~s}^{-1}$ as well as more recent measurements by Fer and Widell [2007] in early spring in Van Mijenfjorden fjord (Svalbard) reporting eddy diffusivity values up to $7.3 \times 10^{-4} \mathrm{~m}^{2} \mathrm{~s}^{-1}$.

[52] Finally, we quantified the mixing rate within the overturning area due mainly to brine release. Energy dissipation reached its highest values up to $O_{\varepsilon}\left(10^{-5} \mathrm{~W} / \mathrm{kg}\right)$, namely two orders or magnitude higher than elsewhere. These results were inferred from Thorpe scale estimated from the size of the overturning events, hence the analysis of these data should be carefully interpreted. Nevertheless the significant increase of mixing rates $\left(K_{\rho} \sim 10^{-3} \mathrm{~m}^{2} \mathrm{~s}^{-1}\right)$ in areas of dense water formation is consistent, and the values compare well with peak values of diffusivity coefficient within the dense water overflow Fer et al. [2004].

[53] We find here that two main processes, tides and brine release, contribute to diapycnal mixing. The first process involving barotropic tides and subsequent baroclinic wave generation constitutes one permanent energy source that sustains production of turbulent kinetic energy. In contrast, the second process occurs sporadically in winter but the intensity of the resulting mixing is higher by two orders of magnitude. Nevertheless we found that baroclinic waves can impact the local heat budget and lead to significant local heating and cooling rates. Note that other mechanisms can lead to an enhancement of diapycnal mixing under the ice layer such as stress at the ice-water interface. In this case the dissipation rate $\varepsilon$ is expected to depend on the speed of the surface layer relative to the ice, $\left|U_{\text {rel }}\right|$. The question of the occurrence of this mechanism was addressed using "Ice-T" 

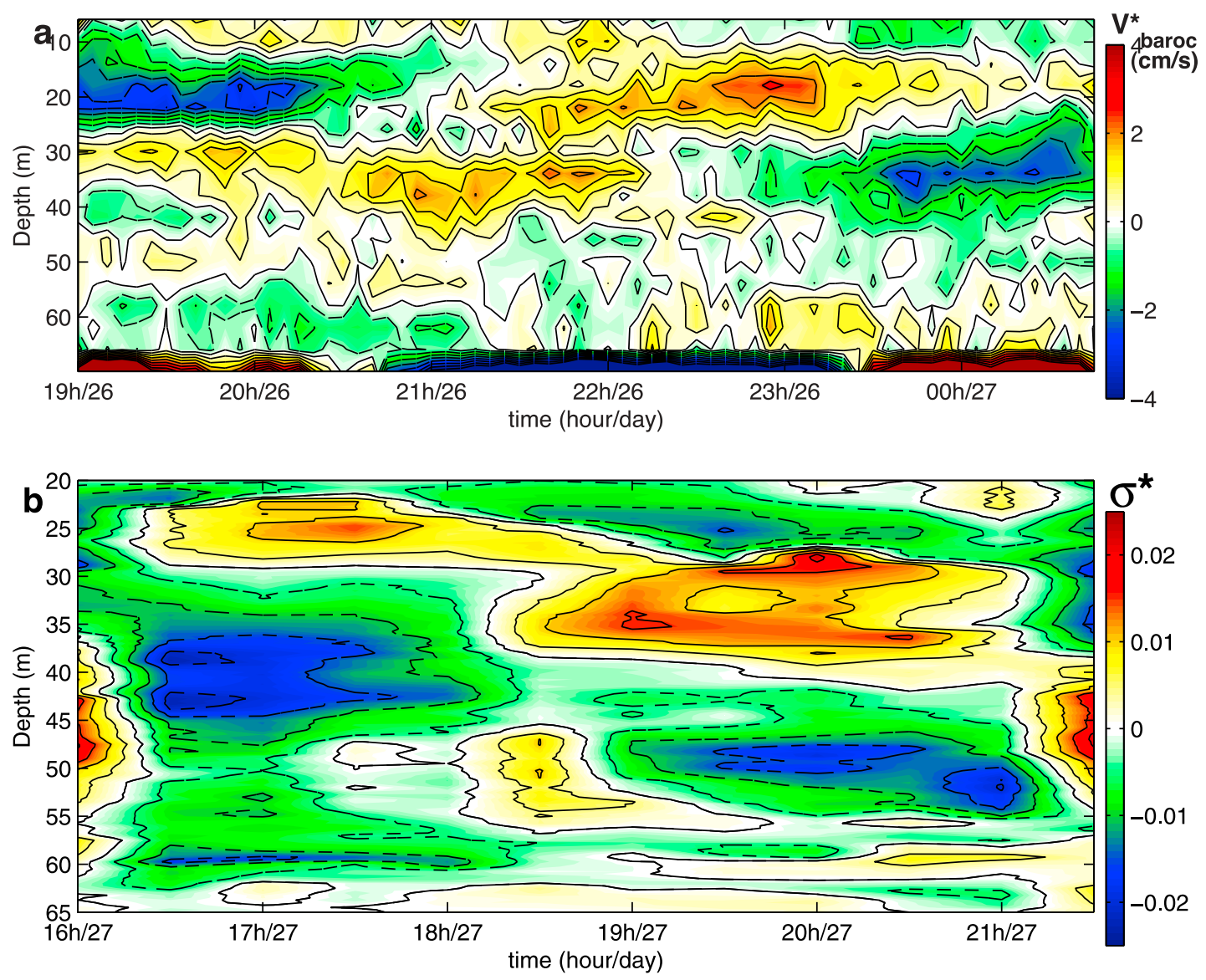

Figure A1. Time-depth evolution of (a) meridional baroclinic current anomalies and (b) potential density anomalies. Notice that velocity and density measures (abscise axis) are not in simultaneous. Positive values are indicate by black solid lines whiles negative values are indicated by black dashed lines for both figures.

measurements to infer relative ice-ocean velocity (not shown). We did not find a significant correlation between these two quantities showing that this process does not occur at the mooring location.

[54] One of the motivations for evaluating diapycnal diffusivity in this specific region was to assess the importance of mixing in controlling the ocean-ice heat flux and ultimately the sea ice mass balance. Using estimates found in this paper, we are currently engaged in diagnosing the heat budget of the topmost ocean layer.

\section{Appendix A: Characterization of Internal Waves and Mixing Either From ADCP or CTD Measurements at a Fixed Point}

[55] A fixed-point station with LADCP (Lowered Acoustic Doopler Profiler) profiles and repeated CTD (ConductivityTemperature-Depth) profiles was scheduled at the location of the middle mooring recovery in late April 2007. Unfortunately, due to a failure of the LADCP, only consecutive LADCP and CTD measurements were collected without any time overlap. This data set thus involves $7 \mathrm{~h}$ of LADCP measurements with $4 \mathrm{~m}$ depth bins and 4 min time sampling, starting on 26 April at $18 \mathrm{~h}$ and 26 CTD casts at 30-minute interval starting on 27 April at $14 \mathrm{~h}$. This data set, though incomplete, allows us to characterize internal waves at intermediate to high frequencies and to have a direct estimate of mixing using Thorpe scale [Thorpe, 1977] inferred from the CTD measurements at 1-m resolution. We thus take benefit of this estimate to test the relevance of the parameterization based on potential energy that was used for the MM.

\section{A1. Internal Waves}

[56] Internal waves were characterized using both LADCP and CTD measurements (Figures Ala and A1b). To give better evidence of baroclinic waves, anomalies of the baroclinic horizontal current and potential density are displayed. The baroclinic current anomaly field was computed by subtracting the time averaged baroclinic current from the total baroclinic current. The same procedure was applied for potential density anomalies $\left(\sigma^{*}\right)$ based on the first 6 hours of the CTD data for consistency.

[57] The temporal evolution of both variables reveals a main oscillation at about a 6-h period over all the stratified column water. Note that the water column is fairly stratified with a mean buoyancy period of 15 min and a minimum buoyancy period of $8 \mathrm{~min}$ encountered in two pycnoclines (see Figure A2). Thus the 4-min sampling of LADCP measurements allows a fairly good characterization of the 


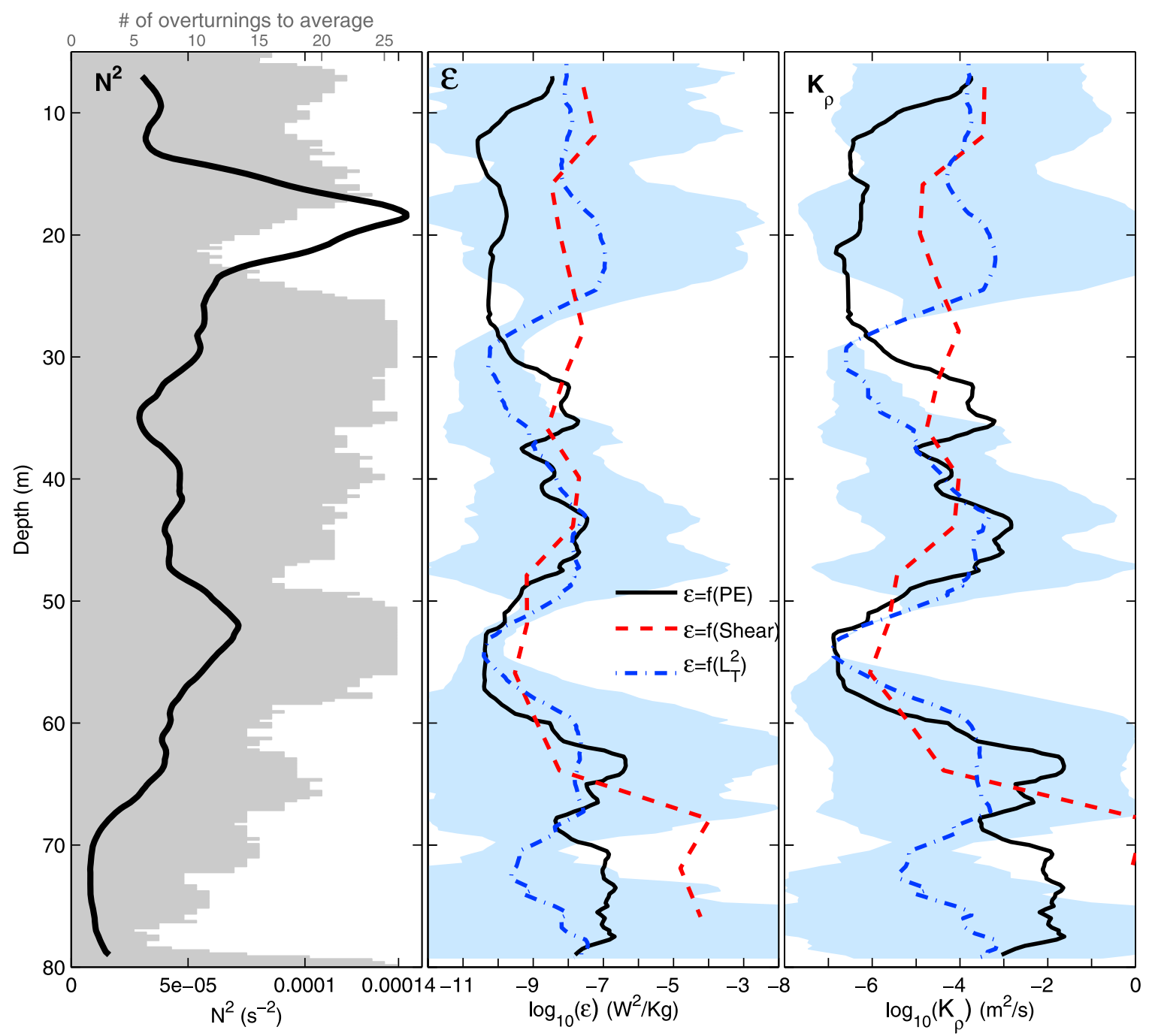

Figure A2. (left) Profile of time-averaged Brunt-Vaisala frequency $\left(\mathrm{N}^{2}, \mathrm{~s}^{-2}\right.$, black solid line), the water column is well stratified with a strong (moderate) intensification of the vertical density structure at 20 and $55 \mathrm{~m}(10$ and $40 \mathrm{~m})$. Grey area identifies the number of values considered for the time-average profiles of $\varepsilon$ and $\mathrm{K}_{\rho}$ based on Thorpe scale. (middle) Turbulent dissipation rate $(\varepsilon)$ from three different methods (1) Potential energy ratio $\left(P E / P E_{G M}\right)$ (black line), (2) Shear ratio $\left(S_{10} / S_{G M}\right)$ (red dashed line) and (3) Thorpe scale $\left(\mathrm{L}_{T}\right)$ (blue dashed-dotted line). (right) Vertical eddy diffusivity based on Osborn model from the $\varepsilon$ showed in Figure A2 (middle) (same color and line style criterion). Light blue areas represent \pm 2 std related to the $\varepsilon$ and $K_{\rho}$ mean.

intermediate- to high-frequency domain of the internal wavefield. A spectral analysis of $V_{\text {baroc }}$ (not shown) gave evidence of waves with shorter periods of $3 \mathrm{~h}, 2 \mathrm{~h}$ and $\sim 10 \mathrm{~min}$ which is close to N. This suggests that as obtained for the MM data, the tidal forcing is a main driver of the wavefield. A careful look at the baroclinic velocity and potential density anomalies, $V_{\text {baroc }}{ }^{*}$ and $\sigma$, suggests the existence of vertically propagating waves. Focusing on the velocity field (Figure A1a), we can observe during the first almost $4 \mathrm{~h}$ a downward phase propagation which implies an upward energy propagation followed by an upward phase propagation implying a downward energy propagation. This suggests an event of internal wave reflection near the surface. Similary, downward phase propagation which implies an upward energy propagation is observed from $\sigma^{*}$.

\section{A2. Vertical Mixing}

[58] Vertical mixing is inferred using the Thorpe scale method which allows us to test the relevance of the parameterization applied in the paper. Dissipation rate is inferred from the Thorpe scale $\left(\mathrm{L}_{T}\right)$ [Thorpe, 1977] assuming a linear relationship between Thorpe and Ozmidov scales: $\varepsilon=0.64 L_{T}^{2} N^{3}$ [Dillon, 1982]. This method thus provides a direct estimate of mixing in regions where overturns are resolved by the CTD measurements, giving an upper bound of the mean dissipation. Vertical profiles of the mean dissipation $(\varepsilon)$ and the mean turbulent diffusivity $\left(\mathrm{K}_{\rho}\right)$ are displayed in Figure A2, jointly with the number of overturnings contributing to the mean value as well as \pm 2 std. Mean dissipation values range between $1.7 \times 10^{-7}$ and $3 \times 10^{-11} \mathrm{~W} \mathrm{~kg}^{-1}$ with higher values around 20, 40 and $65 \mathrm{~m}$, while turbulent diffusivity lie within 
$\left[10^{-7}, 10^{-3}\right] \mathrm{m}^{2} \mathrm{~s}^{-1}$. The fine-scale parameterization based on potential energy, displayed in black, differs from this direct estimate by typically less than a factor of 10 , for both $\varepsilon$ and $K_{z}$. This slight underestimate by the fine-scale parameterization is consistent with the fact that the mean profiles inferred from the Thorpe method only take into account the highest values within overturning regions. In addition, the regions for which larger deviations are obtained within a factor of 100 are less significant since the number of points involved in the Thorpe calculation is much smaller (at depth of about $20 \mathrm{~m}$ and $75 \mathrm{~m}$ ). Thus we can conclude from this comparison that the fine-scale parameterization based on potential energy is relevant.

[59] The parameterization based on shear is shown as well. The estimates of $\varepsilon$ and $K_{z}$ are of the same order of magnitude as those obtained with the Thorpe method which is consistent with the fact that the dynamics does not differ significantly between the two time intervals of ADCP and CTD measurements. This also tends to suggest the agreement between the two parameterizations, based on shear and potential energy, on our data set characterized by internal waves of a wide range of frequencies between $f$ and $\mathrm{N}$. In conclusion the two parameterizations reproduce the vertical structure of dissipation and eddy diffusivity over the water column, with increased values in the upper and lower layers, thus providing a validation for its application on our mooring data set.

[60] Acknowledgments. Hydrographic data were collected as part of the IceDyn campaign funded by IPEV (program 1058) and analyses were carried out as part of the OPTIMISM project (ANR-09- BLAN-0227-01; IPEV 1015). We are grateful to the DAMOCLES EU integrated project. We warmly thank Eric Brossier and France Pinczon du Sel from the Polar Yacht "Vagabond" for hosting us and for their invaluable help during operations. We are indebted to the crew of $\mathrm{R} / \mathrm{V}$ Lance for recovering the main mooring. The high resolution bathymetry of Storfjorden was kindly provided by R. Skogseth. FJ is supported by the Programme AlBan, the European Union Programme of High Level Scholarships for Latin America, scholarship E07D403997AR with additional support from CNES.

\section{References}

Albretch, N., R. Vennell, M. Williams, C. Stevens, P. Langhorne, G. Leonard, and T. Haskell (2006), Observation of sub-inertial internal tides in McMurdo Sound, Antarctica, Geophys. Res. Lett., 33, L24606, doi:10.1029/ 2006 GL027377.

Baines, P. G. (1986), Internal tides, internal waves and near-inertial motions, in Baroclinic Processes on Continental Shelves, Coastal Estuarine Sci. Ser., vol. 3, edited by C. N. K. Mooers, pp. 19-31, AGU, Washington, D. C.

Barry, M. E., G. N. Ivey, G. N. Winters, and J. Imbergen (2001), Measurements of dyapicnal diffusivities in stratified fluids, J. Fluid Mech., 442, 267-291.

D'Asaro, E. A., and J. H. Morison (1992), Internal waves and mixing in the Arctic Ocean, Deep Sea Res., 39, S459-S484.

Desaubies, Y. F. (1976), Analytical representation of internal wave spectra, J. Phys. Oceanogr., 6, 976-981.

Dillon, T. M. (1982), Vertical overturns: A comparison of Thorpe and Ozmidov length scales, J. Geophys. Res., 87, 9601-9613.

Fer, I., and K. Widell (2007), Early spring turbulent mixing in an icecovered Arctic fjord during transition to melting, Cont. Shelf Res., 27, 1980-1999.

Fer, I., R. Skogseth, and P. Jaccard (2003), Observations of the Storfjorden overflow, Deep Sea Res., 50, 1283-1303.

Fer, I., R. Skogseth, and P. M. Haugan (2004), Mixing of the Storfjorden overflow (Svalbard Archipelago) inferred from density overturns, J. Geophys. Res., 109, C01005, doi:10.1029/2003JC001968.

Fer, I., R. Skogseth, and F. Geyer (2010), Internal waves and mixing in the Marginal Ice Zone near the Yermak Plateau, J. Phys. Oceanogr., 40, 1613-1630.

Garrett, C., and W. Munk (1972), Space-time scales of internal waves, Geophys. Astrophys. Fluid Dyn., 2, 255-264.
Garrett, C., and W. Munk (1975), Space-time scales of internal waves: A progress report, J. Geophys. Res., 80, 291-297.

Gerkema, T., and V. Shrira (2005), Near-inertial waves on the "nontraditional" $\beta$ plane, J. Geophys. Res., 110, C01003, doi:10.1029/2004JC002519.

Gregg, M. (1989), Scaling turbulent dissipation in the thermocline, J. Geophys. Res., 94, 9686-9698.

Halle, C., and R. Pinkel (2003), Internal wave variability in the Beaufort Sea during the winter of 1993/1994, J. Geophys. Res., 108(C7), 3210, doi:10.1029/2000JC000703.

Hendershott, M. C. (1981), Pressure ridge gerenated internal wave wakes at the base of the mixed layer in the Arctic Ocean, in Evolution of Physical Oceanography: Scientific Surveys in Honor of Henry Stommel, chap. 10, pp. 292-341, edited by B. A. Warren and C. Wunsch, MIT Press, Cambridge, Mass.

Henyey, F., J. Wright, and S. Flatte (1986), Energy and action flow through the internal wave field: An Eikonal approach, J. Geophys. Res., 91, 8487-8495.

Huthnance, J. (1981), Large tidal currents near Bear Island and related tidal energy losses from the North Atlantic, Deep Sea Res. Part I, 28(1), 51-70. Ivey, G. N., K. B. Winters, and J. R. Koseff (2008), Density stratification, turbulence, but how much mixing?, Annu. Rev. Fluid Mech., 40, 169-184.

Kunze, E. (1985), Near-inertial wave propagation in gresotrophic shear, J. Phys. Oceanogr., 15, 544-565.

Levine, M. (1990), Internal waves under the Arctic pack ice during the Arctic Internal Wave Experiment: The coherence structure, J. Geophys. Res., 95, 7347-7357.

Levine, M., C. Paulson, J. Morison, and J. Morison (1985), Internal waves in the Arctic Ocean: Comparition with lower-latitude observations, J. Geophys. Res., 15, 800-809.

Levine, M., C. A. Paulson, and J. Morison (1987), Observations of internal gravity waves under the Arctic pack ice, J. Geophys. Res., 92, 779-782.

Lindsay, R. W., R. Kwok, L. de Steur, and W. Meier (2008), Halo of ice deformation observed over the Maud Rise seamount, Geophys. Res. Lett., 35, L15501, doi:10.1029/2008GL034629.

MacKinnon, J. A., and M. C. Gregg (2003), Mixing on the late-summer New England Shelf-Solibores, shear, and stratification, J. Phys. Oceanogr., 33, 1476-1492.

MacKinnon, J. A., and M. C. Gregg (2005), Spring mixing: Turbulence and internal waves during restratification on the New England Shelf, J. Phys. Oceanogr., 35, 2425-2443.

Morison, J. H. (1986), Internal waves in Arctic Ocean: A review, in The Geophysics of Sea Ice, edited by N. Untersteiner, pp. 1163-1183, Plenum, New York.

Munk, W. (1981), Internal waves and small-scale processes, in Evolution of Physical Oceanography, edited by B. A. Warren and C. Wunsch, chap. 9, pp. 292-341, MIT Press, Cambridge, Mass.

Naveira Garabato, A. C., K. I. C. Oliver, A. J. Watson, and M.-J. Messias (2004), Turbulent diapycnal mixing in the Nordic seas, J. Geophys. Res., 109, C12010, doi:10.1029/2004JC002411.

Olbers, D. J. (1983), Models of the oceanic internal wave field, Rev. Geophys., 21, 1567-1606.

Osborn, T. (1980), Estimates of the local rate of vertical diffusion from dissipation measurements, J. Phys. Oceanogr., 10, 83-89.

Padman, L. (2004), A barotropic inverse tidal model for the Arctic Ocean, Geophys. Res. Lett., 31, L02303, doi:10.1029/2003GL019003.

Padman, L., and T. Dillon (1991), Turbulent mixing near the Yermak Plateau during the Coordinated Eastern Arctic Experiment, J. Geophys. Res., 96, 4769-4782.

Padman, L., A. J. Plueddemann, R. D. Muench, and R. Pinkel (1992), Diurnal tides near the Yermak Plateau, J. Geophys. Res., 97, 12,639-12,652.

Pawlowicz, R., B. Beardsley, and S. Lentz (2002), Classical tidal harmonic analysis including error estimates in MATLAB using T-TIDE, Comput. Geosci., 28, 929-937.

Percival, D. B., and A. T. Walden (1993), Spectral Analysis for Physical Applications: Multitaper and Conventional Univariated Tecniques, Cambridge Univ. Press, Cambridge, U. K.

Perkin, R. G., and E. L. Lewis (1984), Mixing in the West Spitsbergen Current, J. Phys. Oceanogr., 14, 1315-1325.

Plueddemann, A. (1992), Internal wave observations from the Arctic Environmental Drifting Buoy, J. Geophys. Res., 97, 12,619-12,638.

Polzin, K., J. M. Toole, and R. W. Schmitt (1995), Finescale parameterization of turbulent dissipation, J. Phys. Oceanogr., 25, 306-328.

Quadfasel, D., B. Rudels, and K. Kurz (1988), Outflow of dense water from a Svalbard fjord into the Fraim Strait, Deep Sea Res., 35, 1143-1150.

Rainville, L., and P. Winsor (2008), Mixing across the Arctic Ocean: Microstructure observations during the Beringia 2005 Expedition, Geophys. Res. Lett., 35, L08606, doi:10.1029/2008GL033532.

Rigby, F. A. (1976), Pressure ridge gerenated internal wave wakes at the base of the mixed layer in the Arctic Ocean, M.S. thesis, Univ. of Wash., Seattle. 
Romea, R. D., and J. S. Allen (1983), On vertically propagating coastal Kelvin waves at low latitudes, J. Phys. Oceanogr., 13, 1241-1254.

Schauer, U. (1995), The release of brine-enriched shelf water from Storfjord into the Norwegian Sea, J. Geophys. Res., 100, 16,015-16,028.

Shih, L. H., J. R. Koseff, G. N. Ivey, and J. H. Ferziger (2005), Parameterization of turbulent fluxes and scales using homogeneous sheared stably stratified turbulence simulations, J. Fluid Mech., 525, 193-214.

Skogseth, R., P. Haugan, and M. Jakobsson (2005a), Water mass transformations in Storfjorden, Cont. Shelf Res., 25, 667-695.

Skogseth, R., I. Fer, and P. Haugan (2005b), Dense-water production and overflow from an Arctic coastal polynya in Storfjorden, in The Nordic Seas: An Integrated Perspective: Oceanography, Climatology, Biogeochemistry, and Modeling, Geophys. Monogr. Ser., vol. 158, edited by H. Drange, pp. 73-88, AGU, Washington, D. C.

Skogseth, R., L. H. Smedsrud, F. Nilsen, and I. Fer (2008), Observations of hydrography and downflow of brine-enriched shelf water in the Storfjorden Polynya, Svalbard, J. Geophys. Res., 113, C08049, doi:10.1029/ 2007JC004452.

Støylen, E., and J. E. H. Weber (2010), Mass transport induced by internal Kelvin waves beneath shore-fast ice, J. Geophys. Res., 115, C03022, doi:10.1029/2009JC005298.
Sundfjord, A., I. Fer, Y. Kasajima, and H. Svendsen (2007), Observations of turbulent mixing and hydrography in the Marginal Ice Zone of the Barent Sea, J. Geophys. Res., 112, C05008, doi:10.1029/2006JC003524. Thorpe, S. A. (1977), Turbulence and mixing in a Scottish loch, Math Phys. Sci., 286(1336), 125-181.

Vlasenko, V., N. Stashchuk, K. Hutter, and K. Sabinin (2003), Nonlinear internal waves forced by tides near the critical latitude, Deep Sea Res. 50(3), 317-338

Wijesekera, H., L. Padman, T. Dillon, M. Levine, C. Paulson, and R. Pinkel (1993), The application of internal-wave dissipation models to a region of strong mixing, J. Phys. Oceanogr., 23, 269-286.

P. Bouruet-Aubertot, Y. Cuypers, F. P. Jardon, A. Lourenço, and F. Vivier, Laboratoire d'Océanographie et du Climat: Expérimentaions et Approches Numériques, Institut Pierre Simon Laplace, Université Paris VI, 4 Place Jussieu, Tour 45/55, 4ème étage, Boîte 100, Paris F-75005, France. (fernanda.jardon@locean-ipsl.upmc.fr) 